WORKING PAPER - NO. 2021-107

\title{
Do Financial Concerns Make Workers Less Productive?
}

Supreet Kaur, Sendhil Mullainathan, Suanna Oh, and Frank Schilbach JANUARY 2021

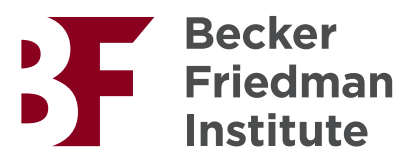


DO FINANCIAL CONCERNS MAKE WORKERS LESS PRODUCTIVE?

\author{
Supreet Kaur \\ Sendhil Mullainathan \\ Suanna Oh \\ Frank Schilbach
}

January 2021

We gratefully acknowledge generous funding and support from the Weiss Family Program for Research in Development Economics, the Eric M. Mindich Research Fund for the Foundations of Human Behavior, the Accountability Group, and the National Science Foundation. Arnesh Chowdhury, Sneha Subramanian, Medha Aurora, Manvi Govil, Piyush Tank, and Pedro Bessone provided excellent research assistance. We thank numerous seminar audiences for helpful feedback, and JPAL and the Institute for Financial Management and Research in India for operational support. This research was approved by MIT IRB (COUHES Protocol 1607623454), Columbia University IRB (IRB-AAAR0033), and by the IFMR Human Subjects Committee (IRB00007107). The study was registered on the AEA RCT registry, RCT ID AEARCTR-0002181.

(C) 2021 by Supreet Kaur, Sendhil Mullainathan, Suanna Oh, and Frank Schilbach. All rights reserved. Short sections of text, not to exceed two paragraphs, may be quoted without explicit permission provided that full credit, including $\odot$ notice, is given to the source. 
Do Financial Concerns Make Workers Less Productive?

Supreet Kaur, Sendhil Mullainathan, Suanna Oh, and Frank Schilbach

January 2021

JEL No. D03,D14,D31,J24,O1

\begin{abstract}
$\underline{\text { ABSTRACT }}$
We test whether increasing cash-on-hand raises the productivity of poor workers. Our motivation is psychological. Concerns about money can create mental burdens such as worry, stress, or sadness. These in turn could interfere with the ability to work effectively. We empirically test for this possibility using a field experiment with piece-rate manufacturing workers in India. We randomize the timing of income receipt, so that on a given day some workers have more cash-on-hand than others. This manipulation holds constant wages and piece rates, as well as human and physical capital. On cash-rich days, average productivity increases by 0.11 standard deviations $(6.2 \%)$; this effect is concentrated among relatively poorer workers. Mistakes also decline on these days --- an effect that is again concentrated among poorer workers. Having more cash-on-hand thus enables workers to work faster while making fewer errors, suggesting improved cognition. We argue that mechanisms such as gift exchange, trust, and nutrition cannot account for our findings. Instead, our results suggest a range of psychological mechanisms wherein alleviating financial concerns allows workers to be more attentive and productive at work.
\end{abstract}

Supreet Kaur

Department of Economics

University of California, Berkeley

Evans Hall

Berkeley, CA 94720

and NBER

supreet@berkeley.edu

Sendhil Mullainathan

Booth School of Business

University of Chicago

5807 South Woodlawn Avenue

Chicago, IL 60637

and NBER

Sendhil.Mullainathan@chicagobooth.edu
Suanna Oh

Paris School of Economics

6th floor, office 38

48 boulevard Jourdan

75014 Paris

France

suanna.oh@psemail.eu

Frank Schilbach

MIT Department of Economics, E52-560

The Morris and Sophie Chang Building

77 Massachusetts Avenue

Cambridge, MA 02139

and NBER

fschilb@mit.edu 


\section{Introduction}

Earning less, almost by definition, is what makes someone poor. The causality, however, might also run in the other direction: being poor may also lead someone to earn less. One well-studied reason is that the poor may lack the money to make productive investments such as education, equipment, or health. While the benefits of these investments can take months or even years to realize, we hypothesize a more direct and immediate way poverty could impede earnings. The poor do not just have less total wealth to make investments. They also face day-to-day financial pressures: needing money for an unexpected expense or shuffling between loans to keep afloat. Making ends meet on a daily basis can create financial concerns resulting in, as recent research argues, worry, stress, or sadness (e.g. Mullainathan and Shafir, 2013; Chemin et al., 2013; Haushofer and Fehr, 2014; Haushofer and Shapiro, 2016). These diverse psychological mechanisms have a shared implication: Workers carry these trouble with them to work, which may make it hard to work effectively. As such, this raises the possibility that the very experience of being poor-having less cash-on-hand-could directly reduce worker productivity.

We test this hypothesis using a field experiment with 408 small-scale manufacturing workers in Odisha, India, who are employed full-time for a two-week contract job-a typical form of employment. Their job is to make disposable plates for restaurants. Though the task is manual labor, it can also be cognitively demanding. Workers are paid piece rates for their output, so that changes in productivity translate into changes in earnings. Our experiment is set during the lean season when people are typically strapped for cash. For example, at baseline, $71 \%$ of workers in our sample have outstanding loans, and $86 \%$ report being worried about their finances (Figure 1). They also carry these concerns with them to work: on any given day, roughly one in two workers reports worrying about their finances while at work.

To study whether having less cash-on-hand hinders productivity, we experimentally alleviate financial constraints for some workers. Specifically, we vary the timing of income receipt, so that some workers receive their earnings sooner than others. These early payments are sizable, equivalent to almost one month's worth of typical labor earnings in the lean season. This large cash infusion appears to immediately reduce financial constraints: within three days, early-payment workers are 40 percentage points $(222 \%)$ more likely to repay their loans. Only the timing of payment changes: the piece 
rate and all other aspects of the job are unchanged. ${ }^{1}$ As such, our treatment aims to reduce short-term financial concerns without affecting overall wealth or financial incentives to work. This design enables us to measure an immediate effect of cash-on-hand on productivity, one that could operate in hours.

We find that alleviating financial constraints boosts worker productivity. The day after receiving a cash infusion, workers are 0.12 standard deviations (SDs) more productive relative to the control group. These gains persist - sustaining throughout the work day and for the remaining days of the treatment period. Moreover, the gains are concentrated among workers who were more financially strained to begin with, measured both by having fewer assets and less liquidity. Early payment increases productivity for these poorer workers by 0.22 SDs. $^{2}$

Our data allows us to measure changes in how workers worked. To produce a leaf plate, irregularly sized leaves must be assembled together to form a clean circle. Doing so efficiently requires planning and focus: to think through how the leaves fit together and to make sure each stitch is in line with that plan. Otherwise, there will be more work: if a plate becomes irregularly shaped, either stitches have to be removed or additional leaves will be needed to compensate - all of which raises the time per plate and reduces the amount a worker can make in a day. Each finished leaf plate contains traces of how attentive a worker was in making it - the number of leaves or stitches used, or pairs of holes that indicate where mistaken stitches were removed - which we measured unbeknownst to workers. The cash infusion treatment not only increases total plates produced, it also appears to improve planning and focus. We find fewer such "attentional lapses" in early payment workers, particularly among the financially strained ones, among whom attentional lapses fell by 0.26 SDs. These reductions also persisted across the remaining days of the contract period.

Are workers more attentive because they are less weighed down by financial concerns or because they are simply more motivated? Could any increase in worker motivation and effort mechanically increase attentiveness? To test this, we experimentally vary

\footnotetext{
${ }^{1}$ This variation does not cause direct wealth effects - only the timing of payment varies. If we see effects from this modest manipulation, then one may expect effects from an unconditional cash transfer, for example, as well. Our manipulation matches an empirical reality for the poor: a wide range of studies indicates that the poor face mounting liquidity constraints and financial stress while waiting for expected income payments to arrive (e.g. Shapiro, 2005; Fehr et al., 2020), and that these may trigger changes in their psychological state (e.g. Mani et al., 2013; Ellwood-Lowe et al., 2020).

${ }^{2}$ These magnitudes are particularly noteworthy given the low wage elasticity of productivity that has been found in many real-effort settings (DellaVigna et al., 2019).
} 
the piece rate between Rs. 2 to Rs. 4, adjusting the base wage to hold overall earnings constant. Each one rupee increase in the piece rate raises output by 0.018 SDs. However, these piece-rate increases produce no discernible change in attentional lapses: the estimated coefficient is essentially zero and significantly different from the output effect $(p=0.004)$. In other words, motivated workers do exert more effort, but are not able to alter their level of attentiveness. These facts together suggest that the productivity effect of being flush with cash is mediated, at least in part, through a mechanism not fully under the control of workers - consistent with some psychological mechanisms such as worry. ${ }^{3}$ They suggest a model of worker productivity where attentiveness and effort enter separately into the production function; interventions that affect effort (such as the piece rate) and interventions that affect attentiveness (such as financial strain) can operate along different dimensions and be of very different magnitudes. In fact, the reduction in attentional lapses is particularly striking given that workers are working faster: having more cash-on-hand increases pace while simultaneously reducing the rate of mistakes.

These facts might potentially be explained in other ways, as we discuss in detail in Section 6. First, gift exchange and fairness theories suggest if employers pay workers more, they will work harder. Here, we have held total pay constant. Still, perhaps workers view receiving the same amount of pay early as a "gift" of sorts. We use the timing of worker productivity increases to test for this possibility: the days between the announcement of early payment and the actual payday. In fact, productivity does not increase in the days after workers learn of the "gift" - inconsistent with what one may expect under gift-exchange models. This does not appear to be a matter of them distrusting the announcement: workers who will be paid early do not show differential productivity increases when they see the employer follow through on early payment to other workers (whose early payment occurs on an earlier day). ${ }^{4}$ It is also unclear why in this explanation, only the poorer workers would engage in gift exchange or exhibit fairness, with no treatment effects on the other workers. Finally, it is unclear why workers motivated by gift exchange would be more attentive, when those motivated by piece rate incentives are not. Second, we address the possibility that our results are due to workers making other productivity-enhancing investments.

\footnotetext{
${ }^{3}$ Though our goal is not to isolate any particular psychological mechanisms, several-including worries, stress, or sadness - have the property of involuntarily interfering with workers' attention.

${ }^{4}$ Specifically, within each round, we further randomized the day of cash receipt among treated workers, so that some workers were paid early on day 8 and others on day 9.
} 
The immediacy of the effect rules out longer-run investments such as training, and our knowledge of the production function rules out physical equipment investments. One important remaining possibility though is better nutrition. Yet, prior work in health and related fields indicates that nutritional changes require longer horizons to translate to productivity effects (e.g. Gómez-Pinilla, 2008; Schofield, 2014), whereas our results manifest overnight. ${ }^{5}$ In addition, we directly measure workers' breakfast intake (all of them are fed the same food after arriving to work, e.g. lunch) and find it is unaffected by early payment. Though plausible ex ante, we argue neither confound appears to explain our results.

Finally, motivated by the prior psychological literature (e.g. Mani et al., 2013), we cross-randomized a priming intervention: some workers were asked in the morning of one workday to recount their outstanding loans and think about how they would come up with a large sum in an emergency. Our hypothesis was that the prime would affect cash-rich workers less, so the productivity effect of priming should be less positive when workers are cash-poor. We find suggestive but not statistically significant evidence of such a differential effect. However, the main effect of the prime intriguingly is positive, which could have various explanations. ${ }^{6}$ For example, the wording of the prime may itself have served as an encouragement to work harder, as in Karlan et al. (2016). These findings, coupled with a growing concern in psychology about the reliability of priming (Kahneman, 2012; Molden, 2014), suggest that rather than using attention as a treatment, it might be more effective to use it as an outcome.

We view the primary contribution of our paper as establishing a direct and immediate impact of cash-on-hand on worker productivity and earnings - one that operates distinctly outside of traditional investment channels such as human or physical capital investments. We document that a cash infusion can directly boost productivity holding fixed all other aspects, including workers' occupation, hours worked, and other inputs. This novel finding complements existing studies showing that comprehensive interventions that transfer assets and skills to poor workers can boost their labor supply and productivity (e.g. Banerjee et al., 2015, 2020; Bandiera et al., 2017; Balboni et

\footnotetext{
${ }^{5}$ In addition, while the workers in our sample are poor, they are not at subsistence - for example, at baseline, $94 \%$ of our sample reported not missing any meals in the previous week-limiting the potential scope for large productivity gains from simply increasing calories.

${ }^{6}$ Recent evidence indicates that increased focus on money due to scarcity also produces some benefits: Shah et al. (2015) show that the poor are less affected by framing effects, and Fehr et al. (2020) find that scarcity reduces the endowment effect. This may help explain the overall positive effect of priming, and counteract our prediction that cash-poor workers will have less positive effects.
} 
al., 2020; Blattman et al., 2015; Bedoya et al., 2019). ${ }^{7}$ We highlight another way such increases could happen, other than through investment. In addition, the time frame of our design establishes the potentially immediate nature of feedback effects - opening new possibilities for how anti-poverty programs could deliver benefits to individuals.

Our study also contributes to the nascent but growing literature on the psychology of poverty (Haushofer and Fehr, 2014; Schilbach et al., 2016). Existing studies have examined the effects of financial constraints using laboratory measures or self-reported psychometric scales. This includes measures of cognitive function, such as Raven's Matrices (Mani et al., 2013; Carvalho et al., 2016; Lichand and Mani, 2019); decisionmaking and preferences, such as time discounting (Shah et al., 2015; Ong et al., 2019; Fehr et al., 2020; Bartos et al., 2018); or psychological well-being, such as happiness or depression (Haushofer and Shapiro, 2016, 2018; Green et al., 2016). ${ }^{8}$ We advance this literature by testing for impacts on high-stakes field behavior - worker productivitywith direct consequences for earnings.

Finally, our results have potential relevance for the poverty traps literature. Existing work has largely focused on neoclassical channels such as capital market imperfections (e.g. Dasgupta and Ray, 1986; Kraay and McKenzie, 2014; Ghatak, 2015; Balboni et al., 2020). Our evidence suggests psychological factors, such as attention, could also play a role in creating poverty traps (Banerjee and Mullainathan, 2008).

\section{Context: Financial Concerns}

We undertake our study with low-income workers engaged in small-scale manufacturing in Odisha, India. In this area, laborers work in agriculture during peak planting and harvesting, which comprise about 4 to 6 months of the year. In the remaining lean agricultural months, they typically seek short-term contract employment in nonagricultural jobs, such as manufacturing and construction. However, such jobs are not easy to find and employment rates are low—with workers finding wage employment only 1.9 days per week on average during lean months (Appendix Table A1, Panel A). Such low lean season employment rates are consistent with those found in other studies

\footnotetext{
${ }^{7}$ In closely related work, Banerjee et al. (2020) document that individuals who receive a livestock asset transfer - shifting them from being wage laborers to increased time as farmers - are more likely to be willing to engage in and increase productivity in a bag-sewing task.

${ }^{8}$ For reviews, see Mullainathan and Shafir (2013), Haushofer and Fehr (2014), and Kremer et al. (2019). A notable exception is Duquennois (2019), who shows that low-income students who encounter a math question that is phrased in terms of money do worse on subsequent questions.
} 
in rural India (e.g. Muralidharan et al., 2016; Breza et al., 2020). This low employment leads to high levels of financial constraints, especially among workers who are dependent on wage labor for their primary earnings (i.e. who own little or no farmland). We conduct our experiment within this context, during the lean season.

In our sample, 71 percent of workers report outstanding loans (Appendix Table A1, Panel B). Over $50 \%$ have outstanding credits with local shops for basic household consumption, indicating difficulties in meeting basic daily expenditures. ${ }^{9}$ Overall, $68 \%$ of workers say they would have difficulty coming up with Rs. 1,000 (i.e. 4 days of wage labor income) in case of an emergency -indicating a low level of cash-on-hand. These patterns, while stark, are not unique to our setting. The poor report low levels of cash-on-hand and difficulty in coming up with the liquidity to cope with shocks in a range of contexts, including in the U.S. and in other developing countries (Lusardi et al., 2011; Morduch and Schneider, 2017; Collins et al., 2009).

These financial burdens are reflected in high levels of worries. In Figure 1, we depict workers' self-reports of how thoughts about finances interact with their daily lives. ${ }^{10}$ When asked how concerned they were about their (future) finances, $70 \%$ of workers say they are "very worried". This number rises to $86 \%$ when also including those who said they were "quite worried" (Panel A). Workers' worries arise top of mind often: nearly half $(52 \%)$ report they worry about finances at least once per day, and almost all reporting worrying at least a few times per week (Panel B). When finances do rise top of mind, workers say they ruminate anywhere from a few minutes (29\%) to a few hours $(43 \%)$ to a whole day (10\%) (Panel C). In Panel E, we depict workers' responses to an open-ended qualitative question asking them what makes them think of financial issues; the figure aggregates raw text responses in a word cloud, where larger text denotes phrases that appear more frequently. ${ }^{11}$ The results indicate that the struggle to meet daily expenses and pay off loans looms large.

Perhaps most relevant for our hypothesis, workers bring worries with them to work (Figure 1, Panel D). At the end of one workday, we asked workers an open-ended question about what they were thinking about that day while working - with no prompts

\footnotetext{
${ }^{9}$ Specifically, among the $50 \%$ with outstanding credits, $84 \%$ have credits with shopkeepers. The remaining have credits with neighbors, former employers, etc.

${ }^{10} \mathrm{As}$ our goal is not to distinguish between particular psychological mechanisms, we use the words worry, anxiety, and rumination in their lay sense. Psychologists have more precise definitions and measurement constructs for each these (e.g. Fresco et al., 2002; Zebb and Beck, 1998).

${ }^{11}$ Surveyors entered workers' responses in short phrases or sentences. We visualized their frequency distribution without processing (i.e. without forming unigrams or bigrams) (e.g. Fellows, 2012).
} 
related to finances, so workers could have talked about anything, such as their weekend plans. $50 \%$ of workers reported that they thought about their finances - indicating that, on a given day, one out of two workers was ruminating about financial concerns while at work. After this unprompted question, we then ask workers specifically whether they thought about their finances while working, and $83 \%$ of workers report doing so. ${ }^{12}$ Such motivational data are of course only suggestive; they do not necessarily indicate that financial concerns alter productivity. However, they provide a glimpse into how frequently such worries rise top of mind while individuals are working.

\section{Experimental Design}

Our primary aim is to test for a direct impact of financial constraints on worker productivity. To enable this, we utilize the worksite infrastructure developed by Breza, Kaur and Shamdasani (2018), wherein workers are hired in contract jobs during the agricultural lean season. Workers are employed full-time for two weeks in a small-scale manufacturing task: making disposable plates for restaurants. They are paid piece rates for output, so that changes in output translate directly into changes in earnings. During the experiment, the workers' job is their main source of income, providing an impetus to put in effort-especially given the financial constraints documented above.

\subsection{Treatment: Variation in Cash-on-Hand}

Our design manipulates immediate financial constraints through changes in cash-onhand. Workers enter the experiment with substantial debt and having had low income during the lean season for weeks or months. Workers consequently have little liquidity with which to meet shocks and can struggle to meet expenses, as suggested by Figure 1 in our context, and documented in the lean season in other contexts (e.g. Fink et al., 2018). In such liquidity-constrained environments, having more cash-on-hand today could have large effects (relative to its negligible effect on permanent wealth). We hypothesize that more cash-on-hand will meaningfully alleviate financial concerns.

Cash treatment. To produce variation in cash-on-hand, we randomly pay some workers early. Figure 2 provides an overview of the timeline for a typical experimental round. Control workers receive all their accrued earnings at the end of the contract period (on workday 12). In contrast, treatment workers receive their accrued earnings

\footnotetext{
${ }^{12}$ The results in Figure 1 are very similar if we restrict the sample to those in the control group or those who did not receive priming on the survey day.
} 
to date early - randomly varied to be on either workday 8 or 9 - with the balance of their earnings paid at the end of the contract on day 12 (see Section 3.4 below for implementation details).

This early payment is a substantial cash infusion, corresponding to what workers typically earned in the month before joining the study. ${ }^{13}$ Consequently, in the "postpay" period - the days after the early payment through the end of the contract - some workers are flush with cash while others are not. We examine worker output in this period to test whether there is an immediate effect of cash receipt on productivity.

Announcement. The early payment is not delivered as a surprise. When workers arrive on day 1 , they are told that some workers may receive their earnings in two tranches rather than one, and that each worker's exact payment schedule will be announced in a few days. In the morning of workday 5 , each worker is told individually when he will receive his payment(s). The subsequent "announcement period" between days 5 to 8 enables us to test whether workers immediately react to news of their payment schedule, and more broadly whether we see any changes in productivity in anticipation of cash arrival. We use this for supplementary analyses - for example, as one of our tests for potential confounds such as fairness concerns and gift exchange. In addition, we combine this with variation in when early payment arrived (day 8 vs. 9) to rule out confounds such as trust in the employer (see Section 6).

Discussion. Our manipulation focuses on isolating, if there is one, an effect of cash-on-hand on productivity that could operate immediately, in hours. As discussed below, we supplement these manipulations with outcome measures that might suggest potential (cognitive) mechanisms behind any such effect.

Our cash-on-hand manipulation does not change wealth levels, it only alters the timing of when cash arrives. ${ }^{14}$ Consequently, our test will only have power to detect effects if the psychological impact primarily ensues once workers are actually flush with cash and can spend it - as opposed to the knowledge that cash will arrive by the end of the contract period. This is a strong test relative to, for example, randomizing unconditional cash transfers. If we find impacts under our more modest manipulation, then cash transfers can be expected to have positive productivity effects as well. In

\footnotetext{
${ }^{13}$ This is primarily due to low employment rates in the lean season (see Section 2 and Appendix Table A1).

${ }^{14}$ The treatment could have a modest effect on wealth levels due to the implied 3-day interest rate on the funds: workers could save some interest by paying back loans early. The presence of such wealth effects, which we quantify below, does not alter the core interpretation of our design.
} 
addition, as a design choice, income receipt variation mimics realistic variation in the lives of the poor who often face heightened financial strain toward the end of their income cycles (e.g. Shapiro, 2005; Fehr et al., 2020), which has been hypothesized to trigger changes in their psychological state (e.g. Mani et al., 2013; Ellwood-Lowe et al., 2020). This body of suggestive evidence motivates our prior for why simply changing the date of cash receipt could potentially produce treatment effects.

\subsection{Work Task and Outcomes}

Work Task. Workers produced disposable plates, made from stitching together leaves from sal trees (Figure A.1). Such plates are a ubiquitous local product used, for example, in virtually all low-tier restaurants in the region. The standards for the plates were set by partnering contractors, and all output was sold to restaurants.

Workers were paid a flat base wage for attendance plus a piece rate per completed leaf plate that satisfied the quality standards developed by contractors. To qualify for payment, a leaf plate was required to: (i) meet a minimum size requirement; (ii) have no holes or gaps so that it could hold food (e.g. curry) without leaks; (iii) have all leaf stalks covered by other leaves; and (iv) have the inner center parts placed underneath the outer rings of the plates.

Making leaf plates is physically exacting - stitching plates requires repeated fine motor movement. It is also cognitively demanding. The process begins with leaves that come in irregular (oval) shapes and sizes, and each leaf is different. These varying shapes must be stitched together so as to produce a circular plate. And since each additional leaf takes time to stitch, workers try to use as few leaves as possible. Making leaf plates therefore requires making and adhering to a plan.

The consequences of failing to do so are clear when a watching plates being made. A worker who has not thought things through might find partway through making a plate that the shape has started to veer from circular toward oblong, thus requiring him to undo stitches to detach the most recent leaves added to the plate, and re-attach them with different positioning. Or, after joining together a series of leaves, a worker might find that a stem is visible or a small gap has appeared between leaves, leading the worker to patch it with another leaf on top.

When focus wanders, work suffers. Workers may need to use more leaves and stitches to compensate for lack of strategic placement. They may need to undo errors by removing stitches in order to re-arrange leaves. Mental errors consequently come at 
a cost. They increase the time to produce each plate and thus reduce earnings.

Of course, focusing on the task is costly; and as such workers may choose how much focus they devote to the task. The capacity to focus may also vary across workers. The core of our hypothesis is that cash-on-hand reduces the capacity to focus. Concretely, workers making leaf plates may find their mind wandering to their financial concernsand when they come back to task realize they have made a mistake. By raising the cost of focusing, a worker who seeks to trade off the cost and benefits of attentiveness may end up earning less when they have looming concerns.

Outcome: Output. Our main measure of output is the number of accepted leaf plates, measured at the hourly level. We focus on on accepted leaf plates as these determine workers' payment but we also measure rejected leaf plates. Workers quickly learned to meet the required standards such that over $97 \%$ of leaf plates were accepted overall and over $98 \%$ after the baseline period. Given the high acceptance rates, using the completed number of leaf plates yields nearly identical results.

Outcome: Attentiveness index. We hypothesize that cash receipt affects workers' psychological state - easing the mental burdens indicated in Figure 1 and potentially enabling workers to be more attentive at work. We directly test for positive evidence for such a channel by unpacking how workers produce their plates. Specifically, as part of collecting product quality indicators, we measured three unincentivized markers of attentiveness on each plate: (a) the number of "double holes" - the telltale sign that a worker removed a stitch from a plate in order to detach a leaf to undo a mistake; ${ }^{15}$ (b) the number of leaves used; and (c) the number of stitches used. A worker who has to undo fewer mistakes, or who makes a completed plate without using extra leaves or stitches to compensate for poor planning or mistakes can be expected to work faster, spending less time per plate.

We collected these three measures for a subset of hours in each experimental round. Workers were not aware that these dimensions of their output were being measured. We normalize these measures and combine them into an "attentiveness index", with the scale reversed so that a higher value on the index corresponds to improved attentiveness (i.e. fewer double holes, leaves, or stitches). ${ }^{16}$ We also create an indicator of "high

\footnotetext{
${ }^{15}$ When a stitch is removed from the plate, it leaves 2 holes (one at each end of the stitch), indicating that a stitch was undone so that the leaf could be removed and re-positioned.

${ }^{16}$ Specifically, we calculate the average number of leaves, stitches, and double holes per plate during each worker-hour slot. The three measures are normalized using the control group's production (mean and standard deviation) in the post-pay period, and then averaged to created the attentiveness index.
} 
attentiveness", defined as having an index value greater than the median, to show robustness in addition to the linear measure.

If we find that being flush with cash improves attentiveness-leading to fewer mistakes while working and more efficient production - this would be consistent with improved cognition at work. However, this would not distinguish between various psychological mechanisms that could give rise to such improvements, for example, worrying, mind wandering, stress, or affect. Rather, it would indicate that the mechanism at play operates by improving attentiveness at work.

\subsection{Additional Treatments}

We augment our design with two additional pieces of variation.

Priming. Our primary test relies on using real income variation to examine the impact of cash constraints on productivity. As a supplementary exercise, following the previous literature (e.g. Mani et al., 2013), we implemented a priming intervention intended to direct workers' attention to their finances. During this intervention, surveyors told workers about another (fictional) worker's financial strain and then administered a survey asking them to list all their loans, employment opportunities, and discuss their finances. This discussion, conducted as part of a financial planning exercise, lasted about 30 minutes and took place in the morning. Before returning back to work, again following Mani et al. (2013), workers were asked if they were to cover an unexpected large expense, how they would raise the money. Workers were asked to think about this question so that their answers could be discussed at the end of the day with the same surveyor. The "priming" manipulation itself resembles a detailed finances survey - a common activity in standard household surveys.

Note that priming interventions are viewed as not creating new thoughts, but rather giving cues that bring existing associations top of mind-only if they already exist in the subject's mind. From our baseline survey, such thoughts are already on workers' minds (Section 2). The prime merely serves to make those thoughts salient at a specific moment, rather than a later moment. In fact, it is the short-livedness of priming interventions (sometimes on the order of minutes) that makes them weak stimuli (e.g. Molden, 2014; Wentura and Rothermund, 2014). Consequently, we analyze the effects of the intervention in the time window immediately post priming.

Some workers received the priming treatment on day 6 of the study, others on day 10 of the study, and others not at all. We hypothesized that priming would cause two 
competing effects: while bringing financial concerns top of mind could reduce output through a cognition effect, reminding workers about their financial needs could motivate them to work harder, increasing output through an effort effect. ${ }^{17}$ We thus crossrandomized the priming intervention with workers' treatment status for the early cash payments to test our hypothesis that priming would more negatively affect productivity among cash-poor workers (those who received the priming before being paid) compared to its impact on cash-rich workers (those who received the priming after being paid early). Our design enables us to test for this pattern, while also allowing us to estimate the overall effect of priming by comparing all primed workers to those who were not primed at all.

Piece-rate variation. Following the completion of the main experiment, we conducted supplementary short rounds that involved varying piece rates for output. We implemented a separate set of rounds involving workers who had participated in the main experiment, and generated within-worker variation in piece rates across six work days. ${ }^{18}$ We adjusted the base wage to hold overall earnings roughly constant across days. Consequently, the piece-rate variation enables us to examine what happens to output when the marginal return to work has changed, but wealth and financial strain have not. Unlike our main cash-on-hand manipulation, this variation should produce no change in workers' level of mental burdens. ${ }^{19}$

The piece-rate variation uncovers the extent to which output can be changed by conscious effort - when workers are motivated to work harder through increased marginal returns to effort - within the context of our particular task. In addition, we also measure the effects of increased piece rates on the attentiveness measures. This allows us to measure whether workers can be more focused when they are more motivated, in this case by a piece rate. In contrast, psychological mechanisms (e.g. worry) are at least partly beyond a worker's control: A worker who is more motivated may not be able to simply worry less and be more focused. Finally, by comparing the impacts on

\footnotetext{
${ }^{17}$ The prior literature has only examined the negative cognition effect, because the outcomes in prior work were laboratory measures of cognition-providing no scope to examine a positive motivational effect wherein working harder and earning more would help one solve the financial concerns that are now top of mind.

${ }^{18}$ The sample in these extra rounds is balanced between those who were treated (i.e. received early cash) in the main rounds and those who were in the control group. See Section 3.4 for details.

${ }^{19} \mathrm{~A}$ separate literature considers whether very large incentives can deteriorate performance via "choking" (Ariely et al., 2009). However, the size of the incentives required to induce choking are much larger than in our setting.
} 
output and attentiveness, we can examine whether both measures exhibit an inherent correlation or whether one can change without the other.

\subsection{Implementation and Protocols}

We conducted the experiment during the main lean season (between March and June) of 2017 and 2018 in Odisha, India. The main experiment was conducted over 14 experimental rounds across five worksite locations in four districts in Odisha. Our sample is comprised of 408 workers, drawn from 47 villages within daily commuting distance of the five worksites. We lay out our protocols for a typical round below; deviations from these protocols are documented in Appendix A.2.

Recruitment. A few days prior to the start of a new round of experiment, recruiters visited a set of new target villages and advertised the upcoming work opportunity through door-to-door visits and fliers. Potential participants were informed about the location, the tasks that they would be asked to do, the duration of the study, and their potential compensation. Workers were eligible to sign-up if they satisfied the following criteria: (i) aged between 18 and 55, (ii) fluent in Odiya (the local language), (iii) work regularly as wage laborers, and (iv) not migrants (i.e. present in their home village for at least 3 of the past 6 months). All workers were male due to cultural norms that restrict women traveling outside the village for work.

Since the number of interested workers exceeded the worksite capacity in each experimental round, we hired 30 randomly selected workers from the sign-up list for that round. In addition, 5 back-up participants were selected to replace any participants who dropped out of the study during the first three days of a round (i.e. before treatment assignment). The main experiment sample is comprised of 408 male workers from 14 experimental rounds with about 30 workers each. ${ }^{20}$

Worksite setup. Workers worked full-time at the worksite during the contract period, which was 12 consecutive days in a typical round. ${ }^{21}$ Hours matched the norms for casual wage work in the villages corresponding to each round. Work typically began at 8 am or 9 am, and ended between $2 \mathrm{pm}$ and $5 \mathrm{pm}$, with 5 hours of work per day in the modal round. ${ }^{22}$ Workers worked individually in their own personal work areas,

\footnotetext{
${ }^{20}$ This number excludes 21 participants who dropped out in the first four days before the payment schedules (i.e. treatment status) were announced. Each round had 26 to 30 workers each.

${ }^{21}$ It is common for short contract jobs to require attendance on consecutive days.

${ }^{22}$ In 9 rounds, the workday ended at $2 \mathrm{pm}$, when laborers in villages go home to have lunch and rest to avoid the afternoon heat. 5 to 6 hour workdays are common for casual labor jobs in these
} 
where they also ate lunch, physically distanced from other workers; this limited the scope for interactions between workers in order to minimize workers' ability to compare output with each other or engage in social conversation at work.

Workers were told their daily output each day throughout the experiment, limiting any uncertainty about the outstanding payment amount. At the end of day 1, all workers were paid a flat wage of Rs. 250 (about US \$4) as a training wage, with the goal to foster trust in the worksite among workers. ${ }^{23}$ For the remaining days, workers were paid a base wage of Rs. 200 and a piece-rate wage of Rs. 3 per plate. The performance payment comprised about $20 \%$ of the overall payment. To encourage high attendance, workers were given a completion bonus (Rs. 300) if they attended all of days 6 through 11, paid out on the final day of the contract. The completion bonus limits the potential extensive margin labor supply responses to the treatment. This enables us to cleanly investigate our primary research question - whether workers' capacity to be productive is affected by their cash-on-hand-without (selective) attrition induced by absences confounding the analysis. ${ }^{24}$

Payment schedule implementation. When workers were recruited, they expected to receive a training payment at the end of day 1, and receive the rest of their earnings on the final day of the contract. On day 1, when workers arrived to the worksite, they were told that some workers would receive their subsequent payments in two tranches instead of one, and that each worker would be told his payment schedule on day 5. In the morning of day 5 (i.e. the "announcement day"), workers were reminded as a group that each worker would learn his payment schedule that day, and after this, each worker was told his individual payment schedule by his manager.

Importantly, workers' output during the day of the early payment itself did not affect how much they were paid on that day. For example, workers who were paid

areas, especially in the lean season due to elevated heat levels. The other rounds had different daily work schedules, e.g. from 9 to 5 , based on local norms, and some rounds were shorter or longer than 12 days. Appendix A.2 provides additional details.

${ }^{23}$ While larger or additional early payments would have been desirable to foster further trust, they would have eased financial constraints among all workers, thus limiting the potential for the experimental variation to create meaningful differences in financial constraints.

${ }^{24}$ When considering the extensive (labor supply) margin, other forces come into play. Recent research argues that the total effects could be even larger due to a positive labor supply response (Banerjee et al., 2020), though ex ante the extensive margin effect is ambiguous. Our goal is not to characterize the overall policy response from a cash drop, but rather to construct a clean test for whether there is a direct and immediate effect of cash on productivity. If such a relationship does exist, then this would motivate work to examine behavioral responses in policy-relevant settings. 
on the evening of day 8 were paid their earnings from days 2 to 7 only. This was designed to limit payday effects driven by present focus as found in Kaur et al. (2015). While payments were made in private at the end of each day, all workers were aware of payments when they occurred at their worksite.

Measurement of outcomes. At the end of each work hour, staff collected completed leaf plates from each worker, under the premise of clearing work areas. Plates were then counted in a private back room, away from workers. For a subset of days, staff also recorded the number of double holes, leaves, and stitches for every plate produced (the components of the attentiveness index). We had two staff members independently count output and the attentiveness measures, with any discrepancies reconciled by a supervisor through a third count, to minimize measurement error.

Randomization. In each experimental round, workers were randomly assigned to the early-pay cash infusion (treatment) group and half to the control group. In addition, within each round, treatment and control workers were cross-randomized into Wave A or Wave B, which determined the specific timing of treatments. Among treatment workers, those in Wave A received their early payment on day 8, while those in Wave B received theirs on day 9. Workers were also randomly assigned to one of three mutually exclusive arms of the priming intervention: cash-poor priming (i.e. 2 days before their wave's early payment), cash-rich priming (i.e. 2 days after their wave's early payment), or no priming. The priming intervention was cross-randomized with the early-pay treatment assignment, so that in each wave, some treatment and control workers would be assigned to each of the three priming arms. ${ }^{25}$

Supplementary survey data. To maintain a natural work environment and to avoid influencing workers' attention through survey activities, we only collected a relatively small set of survey data. ${ }^{26}$ All study participants completed a short baseline survey that included basic demographics such as age, education, and measures of income and wealth, and information about outstanding loans and financial worries. We use these variables to establish baseline balance across treatment groups and to

\footnotetext{
${ }^{25}$ In rounds 1 to 3 , the early-pay group were over-weighted in the randomization to comprise nearly $70 \%$ of the sample. Starting with round 4 , the sizes of the control group and the early-pay group were approximately equal. Conditional on early-pay treatment status, the sizes of groups that receive a priming intervention on day 6 vs. day 10 vs. not at all, was randomized to be 2:2:1.

${ }^{26}$ For the same reason, we also did not collect attention measures using cognitive tests as described in Dean et al. (2018). The most effective versions of the tests are computerized (e.g. the Psychomotor Vigilance Tasks), which would have been a highly unusual event for most the workers in our sample who were largely unfamiliar with computers.
} 
consider heterogeneous treatment effects.

On the last day of each round, we conducted more intensive endline surveys. These collected information about financial worries as well as expenditure patterns and food consumption over the last 3 to 4 days. Finally, we conducted a short survey on day 10 or 11 asking workers about what they thought about while working earlier that day.

Supplementary piece-rate rounds. We implemented five additional short rounds that involved only randomized piece-rate variation (i.e. none of the above treatments). Workers for these rounds were redrawn from the main experimental sample, one year after the main rounds were conducted. Re-hiring these workers ensured that our estimates are representative of those for our main experimental sample. It also enabled us to hire experienced workers who knew how to make leaf plates from day 1 , avoiding

strong learning trends in the data. These rounds, implemented in March and April 2019, involved a total of 151 workers.

Workers were hired for seven days with piece rates changing across the last six days. On the first day, workers received a flat wage of Rs. 250 with no piece-rate component. In the remaining six days, workers were paid a piece rate of Rs. 2, 3, or 4 in randomized order, with each rate lasting for two consecutive days. This order varied across workers within a round, so that on any given day, a third of workers each faced one of the three piece rates. The base wage was adjusted so that average daily earnings would be approximately similar (about Rs. 270 per day) for all three piece rates (see Appendix A.2 for details). In addition, mirroring the main experimental rounds, workers received an attendance bonus of Rs. 200 if they attended all days, leading to a high attendance rate of $97 \%$ during these rounds.

\section{Data and Empirical Strategy}

\subsection{Summary Stats, Heterogeneity in Financial Strain, and Balance}

Appendix Table A1 presents summary statistics and tests for baseline balance. Column 1 shows means and standard deviations for all control group workers. A typical worker in our sample was about 40 years old and had 4 to 5 years of education. Overall, $72 \%$ of workers reported casual daily labor as their primary source of earnings over the year, and $56 \%$ own some farmland. As discussed in Section 2, workers exhibit substantial financial constraints and worries.

To compute a summary measure of baseline financial strain, we use the last four 
binary variables in Panel A: owning farmland; living in a non-mud house (i.e. constructed of durable material); not having resorted to obtaining food or daily goods on credit from grocers and neighbors; and being able to come up with Rs. 1,000 in an emergency. The first two measures are common indicators of assets in our setting, and the latter two reflect liquidity levels. Workers with more assets or liquidity would be expected to have less financial strain at baseline. We take a simple average of these four binaries to form a financial strain index, where higher values reflect lower strain.

Columns 3 and 5 show means separately for workers with above and below median values of this index, respectively. While all workers in our sample are poor by absolute standards, and report substantive levels of financial concerns, this median split segregates workers with substantively different levels of wealth. For example, $80 \%$ of richer workers own land versus $26 \%$ of poorer ones, and $55 \%$ of richer workers report no difficulty in producing Rs. 1,000 in an emergency versus $11 \%$ of poorer ones. In the experiment, we examine heterogeneity with respect to this index. ${ }^{27}$

The baseline characteristics do not statistically differ between the treatment and control groups overall (Appendix Table A1, Col. 2), indicating a successful randomization procedure. In addition, the treatment and control groups within each of the above and below median wealth categories are also balanced (Cols. 4 and 6, respectively). Appendix Table A2 provides a more detailed set of balance checks.

\section{$4.2 \quad$ Empirical Strategy}

For our primary test of treatment effects of the cash infusion, we run difference-indifferences regressions using panel data at the worker-hour level:

$y_{i r d h}=\beta\left(\right.$ Cash $\times$ Post-Pay $\left._{i r d}\right)+\gamma\left(\right.$ Cash $\times$ Post-Announce $\left._{i r d}\right)+\theta_{i}+\sigma_{d}+\delta_{r h}+X_{i r d h}^{\prime} \lambda+\varepsilon_{i r d h}$

where $y_{i r d h}$ is the outcome of worker $i$ in round $r$ on day $d$ in hour $h$. Cash $\times$ Post-Pay $_{i r d h}$ is an indicator that equals 1 if a worker has received the early cash payment (i.e. corresponding to the treatment group's post-pay period in Figure 2). Cash $\times$ Post-Announce $_{\text {irdh }}$ is an indicator that equals 1 for the treatment group during the days after the payment schedule was announced until early payment was disbursed, and equals zero otherwise (i.e. corresponding to the announcement period for the treatment group in Figure 2).

\footnotetext{
${ }^{27}$ Note that we do not have baseline survey data for one worker due to an administrative oversight; analyses using this heterogeneity are therefore comprised of a sample of 407 workers (instead of 408).
} 
Regressions control for worker $\left(\theta_{i}\right)$, day $\left(\sigma_{d}\right)$, and round times hour-of-the-day $\left(\delta_{r h}\right)$ fixed effects. Finally, the $X_{i r d h}^{\prime}$ includes a vector of supplementary controls, including for whether a worker received the priming intervention that day; we show robustness to including or omitting these priming controls. ${ }^{28}$ In addition, we show robustness to alternate specifications, including both fewer and more detailed sets of fixed effects, with the results virtually unchanged.

The key coefficient of interest is $\beta$, which represents the treatment effect of the early payment on worker output. Specifically, it estimates the difference in output between the treatment and the control groups in the post-pay period, relative to their difference in the baseline period (i.e. before payment schedules were announced). In addition, $\gamma$ estimates the announcement effect - the extent to which the treatment and control group's behavior is different after workers are told their payment schedules, but before any money is paid out. These effects are estimated relative to the baseline period, which is the omitted time category in the regressions.

We also examine treatment effect heterogeneity by baseline financial strain levels, using the financial strain index defined in Section 4.1. We examine effects using both the continuous index measure and a binary split (i.e. above vs. below median) for robustness. Note that for some outcomes such as expenditures, we only have one observation per worker (collected post payment), such that we estimate a simplified version of equation (1), using only cross-sectional variation.

\section{Results I: Impacts of Cash Infusion}

\subsection{Expenditure Patterns}

The early payments provided substantive amounts of liquidity to workers, on average over Rs. 1,400. This amount corresponds to almost one month's typical wages during the lean season, given that the typical worker had 8.6 days of paying wage work in the

\footnotetext{
${ }^{28}$ Because waves $\mathrm{A}$ and $\mathrm{B}$ receive the payment on different days (e.g. day 8 vs day 9) within a round, we also include Post dummies in regressions to absorb level effects for completeness (since these would not be fully absorbed by the day fixed effects in the regressions). The Post-announce control is an indicator that equals 1 during the days after schedule announcement and before the wave's cash infusion (i.e. the Announcement period), and the Post-pay control is an indicator that equals 1 during the days after the wave's cash infusion. In addition, we include controls for whether the production hour allotted to the worker was shorter than the full hour (e.g. if the worker was primed or administered the endline survey during that hour). We also show robustness to priming controls, which include a dummy for all slots occurring after any priming intervention on that day, and its interaction with an indicator for whether a worker actually received a priming intervention.
} 
month preceding the experiment.

Our treatment design rests on the premise that this cash infusion may provide immediate financial relief to workers. Before turning to treatment effects on output, to check this premise, we examine whether the early payment had immediate impacts on treatment workers' expenditures. In Table 1, we present estimates of Intent to Treat regressions at the worker level on expenditures, comparing average expenditures in the 3 days following the early cash payment among treatment vs. control workers.

Upon receiving the cash infusion, many workers immediately use the funds to pay off outstanding loans - a major source of worries at baseline. Within three days of being paid, workers were 40 percentage points (222\%) more likely to pay off loans or credits on average (Panel A, Col. 1). This corresponds to an additional Rs. 270 of repaid loans and credits, a $287 \%$ increase relative to the control group mean (Col. 2).

The treatment also increased other expenditures. Food expenditures increased by Rs. 67 relative to a control group mean of Rs. 270 (Panel A, Col. 3). These estimates indicate a need to consider potential impacts through nutrition channels, which we discuss in Section 6.2. Overall, workers reported increasing their expenditures by Rs. $370(65 \%)$ following the infusion of cash (Col. 4). ${ }^{29}$

These effects appear to be larger among workers who were relatively more financially strained at baseline. Using the financial strain index variable (see Section 4.1), we examine heterogeneous effects in Panel B of Table 1. More financially strained workers were substantively more likely to pay off loans than richer workers (Panel B, Col. 1). Among the most financially strained workers in the sample, with an index score of zero, treated workers were 53 percentage points (279\%) more likely to make any payments towards loans and credits than control workers. ${ }^{30}$ We find some suggestive but not statistically significant evidence of heterogeneous impacts by financial strain for repayment amounts, food, and overall expenditures (Cols. 2-4). Overall, while the cash infusion strongly increased expenditures for poorer workers, we cannot reject that

\footnotetext{
${ }^{29}$ Consistent with previous findings (Evans and Popova, 2017), we do not find any evidence of changes in reported expenses on tobacco and alcohol. However, baseline expenditures in this study population are much lower than found in other parts of India (Schilbach, 2019), possibly reflecting non-priced (e.g. home-made) alcohol consumption or reporting error.

${ }^{30}$ Appendix Table A3 shows heterogeneous effects using a median cut of the financial strain measure. The early payment was not sufficient to completely pay off the average worker's loans. The average worker had about Rs. 10,000 outstanding in loans, with similar values for workers with high and low financial strain. Workers suggested in qualitative debriefs that these payments were used to pay off loans that felt most pressing or worrisome, for example, due to pressure from the lender.
} 
there was no impact for those with lower financial strain (i.e., index value of $1, \mathrm{p}=0.25$ ), though the point estimate for these workers is also positive (Col. 4).

\subsection{Productivity Impacts}

In Table 2, we test whether receiving a cash infusion altered worker productivity. In Panel A, we estimate average treatment effects on the number of accepted leaf plates using the approach outlined in Section 4.2.

Workers who were cash rich (due to the early income receipt) produced an additional 0.24 leaf plates per hour compared to the control group (Col. 1, $\mathrm{p}=0.007$ ), corresponding to a $6.2 \%$ output increase. In normalized terms, these effects correspond to a 0.102 to 0.115 standard deviation increase in output (Cols. 2-5). Column 4 corresponds to the specification in equation (1), reflecting a 0.115 standard deviation effect $(\mathrm{p}=0.048)$. This treatment effect is economically meaningful, especially when compared to the relatively low wage elasticity in this setting (see Section 5.3) and that other researchers have found in real-effort experiments (DellaVigna et al., 2019). These results are highly robust to a variety of alternate specifications - changing controls has almost no impact on the estimated effects (see Appendix Table A4).

These productivity impacts are concentrated among more financially strained workers (Table 2, Panel B). Among financially strained workers, the cash infusion increases average output by a remarkable 0.215 SDs (Col. $2, \mathrm{p}=0.007)$. In contrast, we cannot reject that there is no impact on the output of above median wealth workers $(p=0.965)$. Columns 3 to 6 show heterogeneity using each of the 4 underlying components of the financial strain index, with qualitatively similar results.

There are two potentially complementary interpretations for the stronger impacts among more financially strained workers. First, these workers might have more financial concerns (e.g. loans, worries about finances) to start with, thus increasing the scope for our treatment to reduce such concerns. Alternatively, it is possible that both poorer and richer workers in the sample feel mentally burdened by financial strainsince in absolute terms all workers in our sample are poor-but the intervention was more meaningful for workers with fewer assets and liquidity since it was larger compared to their wealth. The fact that both richer and poorer workers report high levels of baseline worries, and have similar magnitudes of outstanding loans (see Appendix Table A1), is potentially consistent with this second interpretation. ${ }^{31}$

\footnotetext{
${ }^{31}$ Because $86 \%$ of workers report being worried about their finances at baseline, we do not have the
} 
In Figure 3, we plot daily treatment effects. Recall that treated workers receive their payments in the evening before going home for work on day 8 or 9 . We stack these observations so that day 1 corresponds to the first day post-pay for workers, and compare output differences to the baseline period. ${ }^{32}$ The figure indicates that, among more financially strained workers, treatment effects materialize immediately, the day after receiving the cash infusion: when workers return to work the following day, their output increases by 0.22 SDs. These effects persist and even slightly increased for the remaining days of the contract period. ${ }^{33}$

The productivity effects documented above are driven by the intensive margin of productivity per hour. Attendance rates were high during the post-pay period (98.1\%), leaving little scope for extensive margin effects. Consistent with this, there is no discernible effect on attendance (Appendix Table A6, Col. 1). Similarly, there was no scope for treatment response in hours per day as work hours were fixed.

In addition, after training, workers understood how to create plates and modify mistakes to prevent rejections. During the post-pay period, the average share of rejected plates was only $1.3 \%$ in the control group, and we find no significant impacts of the early payment on this share (Col. 2). Consequently, estimates are similar if we use total plates produced rather than accepted plates as output measure (Col. 3).

Finally, it is unlikely that the treatment meaningfully affected paid or unpaid work outside of the experiment. In our particular context, after a day of wage work, workers do not tend to engage in secondary work activities - including self-employment and domestic duties (e.g. collecting firewood). For instance, using data from the same regions of Odisha, India, Breza et al. (2020) find that rural casual workers reported doing any secondary activities after work on only $1.72 \%$ of days.

\footnotetext{
power to look at heterogeneity by self-reported baseline worries.

${ }^{32}$ Note that due to this stacking, we cannot show a full day-by-day event study that encompasses both the announcement period and the post-pay period, because these are different lengths and occur on different days across workers in the same round (based on workers' wave assignments) and also across rounds (due to different announcement period lengths across rounds). Thus, we stack the event study at payment day to cleanly and transparently show effects in the post period relative to the baseline. In Table 5, we show day-by-day treatment effects during the announcement period.

${ }^{33}$ We show regression estimates in Appendix Table A5, Columns 1 to 3. Of course, we cannot make claims about whether treatment effects would persist over a longer time horizon.
} 


\subsection{Attentiveness at Work}

More detailed production measures, beyond total output, provide a window into how workers produce - into mental lapses during production. As described above, we collected three markers of attentional errors, which we combine into an "attentiveness index" and a "high attentiveness" indicator variable.

Being cash rich increased workers' attentiveness, especially among the more financially strained half of the sample (Table 3). Across all workers, we find suggestive evidence of an increase in the attentiveness index (by 0.080 to 0.087 SDs, Cols. 1-2) and a statistically significant increase in the high attentiveness indicator (by 7.7 to 9.7 percentage points, Cols. 5-6). Mirroring the impacts of the cash infusion on productivity, we find robust evidence that these impacts are concentrated among more financially strained workers (Cols. 3-4, 7-8). Among workers with above median financial strain, receiving an influx of cash increased attentiveness by $0.23 \mathrm{SDs}$ (Col. 4). In contrast, we cannot reject there was no change in attentiveness among less financially strained workers in the sample. Again mirroring the impacts on productivity, the effects on attentiveness also persist over the remaining duration of the contract period (Appendix Table A5).

These results indicate that after being flush with cash, financially strained workers engaged in better planning and leaf placement, resulting in fewer mistakes that had to be undone or patched. As described in Section 5.2 above, after training, workers rarely made plates that were rejected. Consequently, the attentiveness index reflects the amount of steps needed for a worker to get to a completed plate, with lower attentiveness increasing the number of steps and therefore time per plate. ${ }^{34}$

We interpret these findings as suggesting that the productivity effects we observe are at least partly mediated through improvements in workers' cognitive engagement while working. ${ }^{35}$ Workers increase their pace of work, reducing time per plate, but do so while simultaneously reducing their rate of mistakes. Such attentional impacts are consistent with a potential range of psychological mechanisms - including cash-on-

\footnotetext{
${ }^{34}$ Note that a plate that scores higher or lower on the attentiveness index is not inherently of different value: contractors and restaurants paid per usable (i.e. accepted) plate.

${ }^{35}$ Potentially consistent with the idea that improved attentiveness reflects improved cognition, we find a strong baseline correlation between workers' attentiveness index and their performance on an incentivized memory task, Corsi, a standard cognitive test in psychology (Appendix Table A7). We undertook this test in the supplementary piece rate rounds only in order to correlate cognitive function with attentiveness. Of course, this is a simple correlation and therefore only suggestive.
} 
hand reducing worries and thus distractions during work, or stress, mental health, or happiness - which could operate by improving attentiveness at work.

\subsection{Piece-Rate Variation: Effort vs. Attentiveness}

We see that early payment increases both the productivity and attentiveness of workers. Perhaps this is happening because workers are simply more motivated; or even more extremely, whenever a worker works harder perhaps both productivity and attentiveness increase. To understand this possibility, it is worth noting that there are two ways workers could change how they make leaf plates. They could increase the pace at which they work: do all the steps required to complete a leaf plate more quickly (e.g. by moving their hands faster), or move more quickly from one leaf plate to the next. Alternatively, they could be more careful - on each plate, planning and focusing, to ensure that fewer errors have to be undone.

This suggests two distinct production inputs: (i) effort and (ii) attentiveness. The concern then might be that more motivated workers generally increase both effort and attentiveness. If this were the case, then we should find that other forms of motivation operate similarly. To study this, we examine the effect of experimentally varied piece rates (see Sections 3.3 and 3.4). Recall that in these rounds, we adjusted the base wage to hold overall earnings roughly constant across days. Consequently, unlike our main cash infusion manipulation, this variation should not change workers' level of mental burdens. This lets us examine the degree to which motivation itself increases both productivity and attentiveness.

We estimate impacts in Table 4. Increasing piece rates modestly but statistically significantly increased productivity (Cols. 1-2). Each 1 rupee increase in the piece rate increased output by 0.018 SDs $(\mathrm{p}=0.026)$. This moderate impact is consistent with studies in other contexts, which often find modest piece-rate elasticities in real-effort experiments (DellaVigna et al., 2019). We interpret the output changes due to piecerate changes as an effort response, i.e. the extent to which output can be changed by conscious effort within the context of our particular task.

In contrast, higher piece-rates did not alter the attentiveness measures (Cols. 3-4). The estimates are close to zero and insignificant. These patterns are similar even when examining effects for high financial strain workers only (Appendix Table A8).

Finally, we can reject that the output and attentiveness effects are the same: a test of equality of coefficients between Columns 1 and 3 in Table 4 has a p-value of 
0.004. This indicates the two measures do not exhibit an inherent mechanical correlation: output can change without any change in attentiveness, suggesting that the attentiveness effects of the cash infusion in Section 5.3 are not simply a byproduct of the productivity effects due to increased effort. ${ }^{36}$ Rather, they reflect a change in how workers produce plates.

These results are consistent with the idea that channels such as worry are not fully in a worker's control. Consequently, a worker who is more motivated by the piece rate may not be able to simply worry less and engage in better focus, planning, or cognition. This potentially suggests a simple reduced-form model of our findings, one in which productivity depends on both effort and attentiveness. Effort is chosen and responsive to motivators like piece rates, whereas attentiveness is less under direct control. Financial strain, via mechanisms such as worry, may reduce attentiveness and therefore productivity in a way that is not fully in a worker's control. Similarly, being motivated by a higher piece rate does not allow a worker, for example, to simply worry less. While speculative, this interpretation matches the findings above. These findings suggest that piece rates and cash infusions thus boost productivity through distinct channels - and as such the two can have very different properties and magnitudes.

\section{Results II: Confounds and Supplementary Tests}

\subsection{Announcement Effects and Perceptions of the Employer}

The goal of our intervention was to manipulate cash-on-hand. However, since the manipulation was delivered by the employer - in the form of early payment - this raises potential concerns that the treatment could have changed workers' perceptions towards the employer. In this subsection, we examine two sets of potential concerns in particular: gift exchange or fairness concerns, and trust toward the employer.

Announcement effects, gift exchange, and fairness. One possible explanation for these results is based in notions of fairness. Research has suggested that if workers feel they have been given a gift of additional pay ("gift exchange"), they might reciprocate by working harder; conversely, if they feel they have been treated unfairly by being

\footnotetext{
${ }^{36}$ While attentiveness and output are not mechanically correlated, we do see suggestive evidence in the observational data that the types of workers who exhibit better attentiveness tend to have higher output at baseline (Appendix Table A7); of course, this is only a correlation.
} 
given lower pay, they may reciprocate by working less hard. ${ }^{37}$ Even though the early payment intervention does not vary the amount of payment, our data suggest workers may value it. Might the act of offering early payment itself therefore be viewed as a gift? Conversely, might workers in the control group who were not offered the early payment view it as an important form of unfairness? While such potential mechanisms are undoubtedly important in a range of settings, four pieces of evidence indicate that these mechanisms are unlikely to drive our observed treatment effects.

First, it is not clear that the most straightforward fairness stories would have predicted our results: that effects are concentrated among more financially strained workers. The gift was the same across all treated workers, so fairness concerns might have suggested all respond to some extent. While ex post one can adjust models to explain this pattern (perhaps by arguing financially strained workers value the "gift" more), it is not obvious ex ante that richer workers should not value it at all.

Second, fairness concerns would need to account for the attentiveness results. Even when motivated for their own personal interest with higher piece rates, workers do not seem to be able to affect attentiveness (Section 5.4). Given this, it is unclear why they would then be able to alter their attentiveness when motivated by a desire to improve output for the employer. In addition, recall that workers were not even aware that any such measures were being collected, making a strategic reason for altering these dimensions less likely. Moving beyond our specific attentiveness measures, workers do not appear to be trying to produce higher-quality plates. In fact, after the cash infusion, treated workers spend less time per plate, speeding through faster in order to earn more money. If treatment workers were somehow reciprocating by trying to increase quality, one may expect this time per plate to go up rather than down.

Third, under these alternate mechanisms, we would expect there to be some impact immediately following the pay schedule announcement on day 5. In other words, as soon as treatment workers learn they will be treated "well" or control workers learn they will be treated "unfairly", there should be some change in their behavior. Even if one thought fairness concerns may be more salient after payment is actually delivered, given the large magnitude of our treatment effects post payment, one would expect at least some response (even if muted) when the news is delivered on day $5 .{ }^{38}$

\footnotetext{
${ }^{37}$ See, e.g., Charness and Kuhn (2011); Gneezy and List (2006); Fehr et al. (2009); Kube et al. (2012); Cohn et al. (2015); Jayaraman et al. (2016); Esteves-Sorenson (2017); DellaVigna et al. (2019).

${ }^{38}$ Recall that workers were told on day 1 that some would be paid earlier than others, and that schedules would be announced on day 5 . On the morning of day 5 , workers were again reminded they
} 
We test for announcement effects in Table 5. Columns 1 and 2 display differencein-differences regressions comparing the output of the treatment group to that of the control group on the day post the announcement (Cash $\times 1$ day post announcement) and the day after that (Cash $\times 2$ days post announcement). We focus on these first two days because not all rounds had longer announcement periods, and we separately estimate output effects on the final day of the announcement period (i.e. the payday, see below). ${ }^{39}$ Under gift exchange or fairness concerns, we would expect the announcement effect coefficients to be positive. However, they are small and statistically indistinguishable from zero, and one of the coefficients is even negative. In Column 3, we examine heterogeneity by financial strain, where the first two rows provide estimates for workers with high financial strain. Even among this subset of workers, we do not see discernible announcement effects. In contrast, recall from Table 2 that the estimated treatment effect on output post early cash payment for high financial strain workers is 0.22 SDs.

Intriguingly, we see suggestive evidence that treated workers begin increasing output on the day that early payment is expected to arrive: The "Cash $\times$ Payment day" coefficient, which captures the treatment effect on the day when payment arrives in the evening, is positive but statistically insignificant. This suggestive effect may reflect anticipation effects of the payment arriving that evening, with financial relief immediately in sight. It is unlikely to reflect payday effects from present focus, as in Kaur et al. (2015), since output on the payday itself did not count towards the early payment amount, thus limiting the scope for such effects. ${ }^{40}$

Finally, one possible concern is that, for some reason, fairness concerns only kick in once payments are actually delivered. Again, this may not be what may expect ex ante under standard fairness models, but one could perhaps construct this prediction by adding features such as salience. As a fourth piece of evidence, we test whether the control group decreases effort after early payments are delivered to treatment workers. To test for this, we exploit a feature of our randomization. Recall that we randomized the treatment group into two subgroups: early payment on day 8 (Wave A) vs. day 9

would be told their payment schedules that day, after which each worker was told his schedule.

${ }^{39}$ The announcement was made on the morning of day 5 . Workers walked or traveled together between the worksites and their villages, so that they would have discussed each other's schedules by the time they returned to work on day 6 . Consequently, even if workers must learn the specific schedules of others, we would expect effects on day 2 post announcement (i.e. day 6).

${ }^{40}$ Output on the payday itself did not count towards earnings paid on days 8 or 9 , in contrast to Kaur et al. (2015); we made this decision to avoid large payday effects and for operational ease. Regardless, our estimates suggest that effects before cash arrives are smaller than post cash infusion. 
(Wave B), as illustrated in the more complete timeline in Appendix Figure A.2. When workers arrive to work on day 9, the Wave A treatment workers have already been paid, and the Wave B treatment workers are going to be paid that evening (and so presumably should not have strong feelings of unfairness). If control workers felt treated unfairly and reduced effort on day 9 - and this is what causes the large treatment effects we see post payment - then we should be able to detect this as a differential drop in the control group's output relative to Wave B treatment on day 9.

To capture such effects, we add the triple interaction "Cash $\times$ Payment day $\times$ Wave B" in Column 4 of Table 5. Under this specification, the double interaction "Cash $\times$ Payment day" captures the payday effect for Wave A (on day 8). The triple interaction captures any incremental payday effect for Wave B (on day 9), i.e. the difference between the payday effect for Wave B vs. the payday effect for Wave A. Under the fairness confound, this triple interaction should be positive: in addition to any potential positive effects for Wave B treatment workers, Wave B control workers would be upset about having witnessed Wave A treatment workers be paid on the previous day and drop effort. However, the coefficient on the triple interaction is negative (though imprecise), inconsistent with the idea that fairness concerns drive the large treatment effects we see. In Column 6, we add heterogeneity by financial strain, and still do not see evidence supporting the fairness story - the interaction term is still not positive when looking only at the more financially strained workers.

Of course, finding a lack of effects from gift exchange or fairness does not detract from their potential relevance in other settings. Rather, we designed our experiment to mitigate the presence of these mechanisms to the extent possible. For example, our setup has several contrasting features with Breza et al. (2018), who find negative morale effects in the same cultural setting. Perhaps most importantly, given that, in this setting, fairness norms over pay levels are stronger than norms over amenities (Kaur, 2019), we designed our study to ensure that there were no actual payment differences across workers (conditional on performance). In addition, we set the reference point so that any shocks were positive (avoiding negative reciprocity or loss aversion effects). The worksites also kept workers socially distanced to mitigate reference group effects. ${ }^{41}$

Finally, while we did not collect data on workers' demand for the different payment

\footnotetext{
${ }^{41}$ In Breza et al. (2018), workers primarily compared themselves to those in the same production unit (3 workers who sat together, ate lunch and took breaks together, etc.), but did not compare themselves to others in the worksite with whom there was little direct interaction. In our setting, the salience of coworkers as a reference group is likely to lie somewhere in between these two extremes.
} 
regimes, evidence from other settings suggests that at least some workers prefer more infrequent payments as a method of commitment savings (Casaburi and Macchiavello, 2019), such that the direction of overall preference would be a priori unclear. This may especially be true if workers are not aware of the extent to which relieving mental burdens could affect their productivity (e.g. Dean, 2020).

Trust in the employer. An additional potential concern is that the early payment could have increased workers' trust that they would get paid in the future. This would change the implied piece rate they actually expect to receive, thereby increase effort and earnings. In anticipation of such concerns, we included several operational features in our design to boost trust. For example, we paid all workers at the end of the first day - in accordance with what workers were told during recruiting - to build trust that we would pay when we promised. We also had a worksite calendar that we announced in advance (e.g. payment schedules announced on day 5) and adhered to it meticulously to instill a feeling of predictability in the worksite. However, despite these efforts, one may be concerned that some residual trust issues remained.

While such an explanation could explain increased output, it is inconsistent with other facts - in particular the pattern of results in Table 5. Under such a story, we might expect the Wave B treatment workers - who saw Wave A workers being paid - to also update their beliefs when they arrive at work on day 9. So they too should increase their output on their payday even before actually being paid in the evening. This would suggest that the coefficient on the triple interaction - Cash $\times$ Payment Day $\times$ Wave B - in Table 5 should be positive. However, this coefficient is insignificant and actually negative in magnitude. Perhaps more problematic for a trust explanation, when Wave A workers are paid on day 8 as promised, it is unclear why this should not boost all workers' confidence that the employer pays out as expected. In other words, it is unclear why seeing some people paid as promised should generate differential changes in relative trust between treatment and control groups. Moreover, such a story would suggest a high rate of responsiveness to increases in the piece rate - a premise that is not supported by the results in Table 4.

\subsection{Investment Channels: Nutrition}

The primary goal of our experiment is to examine whether cash-on-hand has a direct and immediate impact on worker productivity - operating outside of the traditional 
investment-based channels that have been discussed in the literature such as human capital, physical capital, or nutrition. By construction, our design rules out human or physical capital changes. ${ }^{42}$ In this section, we discuss whether changes in nutrition could plausibly drive our finding of overnight increases in productivity.

A long literature in development economics has hypothesized the potential for nutrition to affect productivity (e.g. Dasgupta and Ray, 1986). We find some evidence that workers increase their food expenditures following the cash infusion (Table 1), as discussed in Section 5.1. There are two categories of potential pathways: (i) a change in workers' underlying nutritional stock, and (ii) short-run blood sugar increases from increased food intake for workers who would otherwise feel hungry at work.

The first pathway - biological changes for malnourished workers - is unlikely given the immediate nature of productivity effects in our setting. According to the biological and medical literatures on the impacts of increased food intake, such changes cannot occur overnight (e.g. Gómez-Pinilla, 2008). For example, consistent with slower-moving effects, Schofield (2014) finds evidence of increased earnings among workers only starting a week after increasing their caloric intake. In addition, while the workers in our sample are poor, they are not at subsistence; for example, at baseline, $94 \%$ of our sample reported not missing any meals in the previous week. This lessens the scope for a severe caloric deficit based explanation for the large productivity gains we see.

The second channel is more plausible ex ante, since it occurs through immediate and short-run changes. In our setting, immediate energy increases from eating would need to occur via breakfast intake - leading treated workers to arrive to the worksite with fuller stomachs. This is because once workers arrive at the worksite, there were no differences between them in food intake. In the rounds where the worksite was open longer than $2 \mathrm{pm}$, all workers were provided the same exact lunch at their work stations, and in other rounds, they were provided the same snacks at the end of each day. Beyond these, there was no room for snacking since it was difficult for workers to purchase snacks outside given the rural location of the job sites and the structure of the workday (workers were not allowed to go off site during the work day). In addition, any differences in dinner would not biologically alter energy levels 12 to 18 hours later. Consequently, the only way through which increased food purchases could generate biologically-driven changes in productivity overnight is through breakfast consumption.

\footnotetext{
${ }^{42}$ The time horizon does not allow for human capital investments, and there was no scope for workers to bring any implements or physical capital to the worksite.
} 
We undertook two tests for such a story, shown in Table 6. First, in the expenditure survey, we collected measures of daily breakfast consumption for the days following the early payment day. We find no evidence of increased breakfast on any of the dimensions of our survey, including whether workers had breakfast, how much, and what they ate (Cols. 1 to 5). This appears to be because, in this setting, breakfast consumption is fairly inelastic: almost all workers (98 percent) in the control group reported eating breakfast, thus leaving not much room at the extensive margin, and almost everyone (94 percent) reported eating a particular rice dish that is common in the area.

Second, we would expect any impacts of blood sugar spikes due to increased breakfast consumption to wear off by the end of the work day. However, we find persistent impacts of the early-pay treatment throughout the day, including the last couple of hours or the workday, i.e. 5 to 7 hours after eating breakfast (Cols. 6 to 9).

\subsection{Priming Treatment}

Our primary test relies on using real income variation to examine the impact of cash constraints on productivity. As a supplementary exercise, we followed the previous literature and implemented a priming intervention intended to direct workers' attention to their finances (Mani et al., 2013). This intervention involved asking workers to recall their outstanding loans and think about how they would raise a large sum of money in an emergency. Recall from Section 3.3 that the priming intervention was cross-randomized with the cash infusion treatment, enabling us to examine the relative effects of priming when workers are relatively cash rich vs. cash poor.

Ex ante, directing workers' attention can have two potentially opposing effects. On the one hand, priming the psychological state that accompanies financial strain may lower worker productivity. On the other hand, focusing workers' attention on their finances could increase workers' perceived marginal value of a dollar - since their effort at work can directly help overcome the problems being primed. Such impacts, resembling reminder effects in Karlan et al. (2016), might increase worker effort and thus productivity. Prior work has only focused on the potential negative effects, since the outcomes have been laboratory measures of cognition - providing no scope to examine a positive motivational effect. In our setting, both forces are likely operational, so that the overall effect of priming is ambiguous. Consequently, our (pre-registered) hypothesis was that priming would more negatively affect productivity among cash-poor workers (those who received the priming before being paid) compared to its impact on 
cash-rich workers (those who received the priming after being paid early).

In our setting, the overall impact of the priming intervention on worker productivity is positive (Table A9). After being primed during the first hour of work, hourly production increases by $0.044 \mathrm{SDs}$ (Col. 1) compared to the remaining study samplesuggesting that the motivational effect dominates overall. The positive effects are concentrated among workers who were flush with cash, i.e. when priming was administered after the early cash payment; among these workers, priming increased output by up to 0.078 SDs (Col. 2). In contrast, when workers were cash poor (i.e. before their first major payment), we cannot reject that there is no impact (positive or negative) of the priming treatment on worker productivity. While the negative interaction term in Column 2 matches our ex-ante hypothesis, it is not statistically significant.

The heterogeneous treatment effects (Table A9, Cols. 3-4) highlight the difficulties in targeting priming interventions precisely. Our intention was to target poverty, but we may have instead made loans more salient. This interpretation may explain the lack of heterogeneous treatment effects with respect to financial strain (Col. 3) and the clear evidence of heterogeneous impacts with respect to having loans that workers are worried about (Col. 4). ${ }^{43}$ In our setting, loan amounts and wealth are negatively correlated, potentially helping explain the lack of heterogeneity in Column 3.

Overall, we find an ambiguous set of results of the impact of priming on worker productivity. This accords with the potential messiness of priming highlighted by some psychologists (e.g. Kahneman, 2012; Molden, 2014). ${ }^{44}$ Finally, in understanding the overall level effects of priming, there is an important distinction with our early cash intervention. Priming affects worries, but also directly motivates people by reminding them to work hard to deal with their financial concerns (e.g. Karlan et al., 2016). Our cash intervention, in contrast, mitigates financial concerns without any overt reminders of the need to work hard. Consequently, even if priming were well-targeted and effective, it need not mimic the (reverse) effects of actual increases in cash-on-hand.

\footnotetext{
${ }^{43}$ Specifically, in Column 4, we see no effects of priming on workers who report having no loans about which they are worried at baseline. Among workers who do have such loans - the workers for whom the priming intervention would be most relevant-priming raises output by 0.178 SDs when workers are flush with cash; when workers are cash-poor the differential effect of priming is -0.250 SDs $(\mathrm{p}=0.020)$, suggesting a total effect of $-0.072(\mathrm{p}=0.148)$. More generally, these results indicate that it is difficult to raise the salience of only one particular issue of interest.

${ }^{44}$ For example, priming is likely to be non-monotonic in its effects. One can only bring worries top of mind if they exist, implying larger impacts for those with more financial strain. However, underlying concerns may already be top of mind for such individiauls, leading instead to smaller effects for them.
} 


\section{Conclusion}

We are only beginning to understand the psychological consequences of poverty on economic outcomes. The early work has largely been on laboratory measures of cognition, self-reported well-being, or biomarkers such as stress (Mani et al., 2013; Carvalho et al., 2016; Chemin et al., 2013; Haushofer and Shapiro, 2016, 2018; Ridley et al., 2020). Evidence on economic field behaviors is a necessary next step to understand what implications these have for economic outcomes. Earnings are one such outcome and a particularly important one since its effects are widespread. As such, an impact of financial concerns on earnings could eventually change our thinking about the impediments to escaping poverty and related policies. Though these lessons are down the road, requiring a great deal more empirical work, we suggest three avenues.

First, these effects may cause us to reconsider cash transfer programs (conditional and unconditional). Given our findings, it seems worth revisiting other contexts in search of similar direct effects. For instance, Fink et al. (2018) document increases in on-farm labor supply and harvest output following liquidity drops to Zambian farmers; these increases are also accompanied by potential improvements in decision-making (Fehr et al., 2020). Banerjee et al. (2015) and Bandiera et al. (2017) find large and persistent impacts of bundled treatments to support the ultra-poor. Such impacts are often attributed to neoclassical explanations such as credit constraints (Matsuyama, 2011; Ghatak, 2015). Our evidence suggests that direct effects of changes in financial strain may have contributed to observed impacts in these settings. Moreover, these programs may have broader social returns. Except for self-employed individuals, most workers are not able to internalize the returns of their own productivity. Consequently, transfer programs could have supply-side multiplier effects via higher firm productivity_providing an additional rationale for subsidizing such programs.

Second, we might want to consider more specifically models of worker output that incorporate the effects we have found. For instance, our results could suggest a different interpretation of efficiency wages. Firms may be compelled to voluntarily pay workers more not to enhance nutrition (Dasgupta and Ray, 1986), avoid moral hazard (Shapiro and Stiglitz, 1984), or improve worker selection (Weiss, 1980), but to enhance focus and productivity at work. Disentangling the exact mechanism for our effect could prove fruitful to better understand the nature of these relationships.

Finally, if poverty reduces productivity, it creates a mechanism that amplifies neg- 
ative income or wealth shocks. Faced with a calamity, people would be less productive exactly when they are in greatest need of cash. These problems are especially severe given that in most poor countries, individuals are especially reliant on labor earn-

ings to smooth consumption and self-finance productive investment in their enterprises (Kochar, 1999). Accordingly, if poverty negatively affects productivity, then the benefits of reducing volatility (e.g. through stable employment or public workfare programs) or mitigating financial vulnerability (e.g. through credit access or unemployment insurance) could be larger than predicted in the traditional economics literature.

\section{References}

Ariely, Dan, Uri Gneezy, George Loewenstein, and Nina Mazar, "Large Stakes and Big Mistakes," Review of Economic Studies, 2009, 76, 451-469.

Balboni, Clare, Oriana Bandiera, Robin Burgess, Maitreesh Ghatak, and Anton Heil, "Why Do People Stay Poor?," mimeo, 2020.

Bandiera, Oriana, Robin Burgess, Narayan Das, Selim Gulesci, Imran Rasul, and Munshi Sulaiman, "Labor Markets and Poverty in Village Economies," Quarterly Journal of Economics, 2017, 132 (2), 811-870.

Banerjee, Abhijit and Sendhil Mullainathan, "Limited Attention and Income Distribution," American Economic Review Papers and Proceedings, 2008, 98 (2), 489-493.

_ , Esther Duflo, Nathanael Goldberg, Dean Karlan, Robert Osei, William Pariente, Jeremy Shapiro, Bram Thuysbaert, and Christopher Udry, "A Multifaceted Program Causes Lasting Progress for the Very Poor: Evidence from Six Countries," Science, 2015, 348 (6236).

Banerjee, Abhijit V., Dean Karlan, Hannah Trachtman, and Christopher R. Udry, "Does Poverty Change Labor Supply? Evidence from Multiple Income Effects and 115,579 Bags," NBER Working Paper \#27314, 2020.

Bartos, Vojtech, Michael Bauer, Julie Chytilova, and Ian Levely, "Effects of Poverty on Impatience: Preferences or Inattention?," mimeo, 2018.

Bedoya, Guadalupe, Aidan Coville, Johannes Haushofer, Mohammad Razaq Isaqzadeh, and Jeremy Shapiro, "No Household Left Behind: Afghanistan Targeting the Ultra Poor Impact Evaluation," mimeo, June 2019.

Blattman, Christopher, Eric P Green, Julian C Jamison, M Christian Lehmann, and Jeannie Annan, "The Returns to Microenterprise Support Among the Ultra-Poor: A Field Experiment in Post-War Uganda," American Economic Journal: Applied Economics, 2015, 8 (2), 35-64.

Breza, Emily, Supreet Kaur, and Yogita Shamdasani, "The Morale Effects of Pay Inequality," Quarterly Journal of Economics, 2018, 133 (2), 611-663.

_, _, and _, "Labor Rationing," mimeo, 2020. 
Carvalho, Leandro S., Stephan Meier, and Stephanie W. Wang, "Poverty and Economic Decision-Making: Evidence from Changes in Financial Resources at Payday," American Economic Review, 2016, 106 (2), 260-284.

Casaburi, Lorenzo and Rocco Macchiavello, "Demand and Supply of Infrequent Payments as a Commitment Device: Evidence From Kenya," American Economic Review, 2019, 109 (2), 523-555.

Charness, Gary and Peter Kuhn, "Lab Labor: What Can Labor Economists Learn from the Lab?," in O. Ashenfelter and D. Card, eds., O. Ashenfelter and D. Card, eds., 1 ed., Vol. 4A, Elsevier, 2011, chapter 03, pp. 229-330.

Chemin, Matthieu, Joost de Laat, and Johannes Haushofer, "Poverty and Stress: Rainfall Shocks Increase Levels of the Stress Hormone Cortisol," mimeo, 2013.

Cohn, Alain, Ernst Fehr, and Lorenz Goette, "Fair Wage and Effort Provision: Combining Evidence from a Choice Experiment and a Field Experiment," Management Science, 2015, 61 (8), 1777-1794.

Collins, Daryl, Jonathan Morduch, Stuart Rutherford, and Orlanda Ruthven, Portfolios of the poor: how the world's poor live on \$2 a day, Princeton: Princeton University Press, 2009.

Dasgupta, Partha and Debraj Ray, "Inequality as a Determinant of Malnutrition and Unemployment," Economic Journal, 1986, 96, 1011-1034.

Dean, Emma Boswell, Frank Schilbach, and Heather Schofield, "Poverty and Cognitive Function," in Christopher B. Barrett, Michael R. Carter, and Jean-Paul Chavas, eds., The Economics of Poverty Traps, Chicago: University of Chicago Press, 2018.

Dean, Joshua T., "Noise, Cognitive Function, and Worker Productivity," mimeo, 2020.

DellaVigna, Stefano, John List, Ulrike Malmendier, and Gautam Rao, "Estimating Social Preferences and Gift Exchange with a Piece-Rate Design," mimeo, 2019.

Duquennois, Claire, "Fictional Money, Real Costs: Impacts of Financial Salience on Disadvantaged Students," Unpublished manuscript, 2019.

Ellwood-Lowe, Monica E., Ruthe Foushee, and Mahesh Srinivasan, "What causes the word gap? Financial concerns may systematically suppress child-directed speech," mimeo, 2020.

Esteves-Sorenson, Constanca, "Gift Exchange in the Workplace: Addressing the Conflicting Evidence with a Careful Test," Management Science, 2017, 64 (9), 43654388.

Evans, David K. and Anna Popova, "Cash Transfers and Temptation Goods," Economic Development and Cultural Change, 2017, 65 (2), 189-221.

Fehr, Dietmar, Guenther Fink, and Kelsey Jack, "Poor and Rational: Decisionmaking under Scarcity," mimeo, 2020.

Fehr, Ernst, Lorenz Goette, and Christian Zehnder, "A Behavioral Account of the Labor Market: The Role of Fairness Concerns," Annual Review of Economics, 2009, 1, 355-384.

Fellows, Ian, "wordcloud: Word clouds," $R$ package version, 2012, 2, 109. 
Fink, Günther, Kelsey Jack, and Felix Maxiye, "Seasonal Liquidity, Rural Labor Markets and Agricultural Production," NBER Working Paper No. 24564, 2018.

Fresco, David M, Ann N Frankel, Douglas S Mennin, Cynthia L Turk, and Richard G Heimberg, "Distinct and overlapping features of rumination and worry: The relationship of cognitive production to negative affective states," Cognitive Therapy and Research, 2002, 26 (2), 179-188.

Ghatak, Maitreesh, "Theories of Poverty Traps and Anti-Poverty Policies," Work Bank Economic Review, 2015, 29 (Supplement), S77-S105.

Gneezy, Uri and John A. List, "Putting Behavioral Economics to Work: Testing for Gift Exchange in Labor Markets using Field Experiments," Econometrica, 2006, 74 (5), 1365-1384.

Gómez-Pinilla, Fernando, "Brain foods: the effects of nutrients on brain function," Nature Reviews Neuroscience, 2008, 9 (7), 568-578.

Green, E P, C Blattman, J Jamison, and J Annan, "Does poverty alleviation decrease depression symptoms in post-conflict settings? A cluster-randomized trial of microenterprise assistance in Northern Uganda," Global Mental Health, 2016, 3.

Haushofer, Johannes and Ernst Fehr, "On the Psychology of Poverty," Science, 2014, 344 (6186), 862-867.

- and Jeremy Shapiro, "The Short-Term Impact of Unconditional Cash Transfers to the Poor: Experimental Evidence from Kenya," Quarterly Journal of Economics, 2016, 131 (4), 1973-2042.

_ and _, "The Long-Term Impact of Unconditional Cash Transfers to the Poor: Experimental Evidence from Kenya," mimeo, 2018.

Jayaraman, Rajshri, Debraj Ray, and Francis de Véricourt, "Anatomy of a Contract Change," American Economic Review, 2016, 106 (2), 316-358.

Kahneman, Daniel, "A Proposal to Deal with Questions about Priming," 2012. https://go . nature.com/3nPea6I.

Karlan, Dean, Margaret McConnell, Sendhil Mullainathan, and Jonathan Zinman, "Getting to the Top of Mind: How Reminders Increase Saving," Management Science, 2016, 62 (12), 3393-3411.

Kaur, Supreet, "Nominal wage rigidity in village labor markets," American Economic Review, 2019, 109 (10), 3585-3616.

_ , Michael Kremer, and Sendhil Mullainathan, "Self-Control at Work," Journal of Political Economy, 2015, 123 (6), 1227-1277.

Kochar, Anjini, "Smoothing Consumption by Smoothing Income: Hours-of-work Responses to Idiosyncratic Agricultural Shocks in Rural India," Review of Economics and Statistics, 1999, 81 (1), 50-61.

Kraay, Aart and David McKenzie, "Do Poverty Traps Exist? Assessing the Evidence," Journal of Economic Perspectives, 2014, 28 (3), 127-148.

Kremer, Michael, Gautam Rao, and Frank Schilbach, "Behavioral Development Economics," in B. Douglas Bernheim, Stefano DellaVigna, and David Laibson, eds., Handbook of Behavioral Economics: Foundations and Applications, Vol. 2, Amsterdam: Elsevier/North-Holland, 2019.

Kube, Sebastin, Ernst Fehr, Michel Marechal, and Clemens Puppe, "The Currency of Reciprocity: Gift Exchange in the Workplace," American Economic 
Review, 2012, 102 (4), 1644-1662.

Lichand, Guilherme and Anandi Mani, "Cognitive Droughts," mimeo, 2019.

Lusardi, Annamaria, Daniel J. Schneider, and Peter Tufano, "Financially Fragile Household: Evidence and Implications," Brookings Papers on Economic Activity, 2011, Spring, 83-134.

Mani, Anandi, Sendhil Mullainathan, Eldar Shafir, and Jiaying Zhao, "Poverty Impedes Cognitive Function," Science, 2013, 341 (6149), 976-980.

Matsuyama, Kiminori, "Imperfect Credit Markets, Household Wealth Distribution, and Development," Annual Review of Economics, 2011, 3, 339-362.

Molden, Daniel C., "Understanding Priming Effects in Social Psychology: What Is 'Social Priming' and How Does It Occur?," Social Cognition, 2014, 32 (Supplement), $1-11$.

Morduch, Jonathan and Rachel Schneider, The financial diaries: How American families cope in a world of uncertainty, Princeton: Princeton University Press, 2017.

Mullainathan, Sendhil and Eldar Shafir, Scarcity: Why Having Too Little Means So Much, New York: Macmillan, 2013.

Muralidharan, Karthik, Paul Niehaus, and Sandip Sukhtankar, "Building State Capacity: Evidence from Biometric Smartcards in India," American Economic Review, 2016, 106 (10), 2895-2929.

Ong, Qiyan, Walter Theseira, and Irene Y.H. Ng, "Reducing Debt Improves Psychological Functioning and Changes Decision-making in the Poor," Proceedings of the National Academy of Sciences, 2019, 116 (15), 7244-7249.

Ridley, Matthew, Gautam Rao, Frank Schilbach, and Vikram Patel, "Poverty, Depression, and Anxiety: Causal Evidence and Mechanisms," Science, 2020, 370 (6522).

Schilbach, Frank, "Alcohol and Self-Control: A Field Experiment in India," American Economic Review, 2019, 109 (4), 1290-1322.

_ , Heather Schofield, and Sendhil Mullainathan, "The Psychological Lives of the Poor," American Economic Review, 2016, 106 (5), 435-440.

Schofield, Heather, "The Economic Costs of Low Caloric Intake: Evidence From India," mimeo, 2014.

Shah, Anuj K., Eldar Shafir, and Sendhil Mullainathan, "Scarcity Frames Value," Psychological Science, 2015, 26 (4), 402-412.

Shapiro, Carl and Joseph E. Stiglitz, "Equilibrium Unemployment as a Worker Discipline Device," The American Economic Review, 1984, 74 (3), 433-444.

Shapiro, Jesse M., "Is There a Daily Discount Rate? Evidence From the Food Stamp Nutrition Cycle," Journal of Public Economics, 2005, 89 (2-3), 303-325.

Weiss, Andrew, "Job queues and layoffs in labor markets with flexible wages," Journal of Political economy, 1980, 88 (3), 526-538.

Wentura, Dirk and Klaus Rothermund, "Priming is not Priming is not Priming," Social Cognition, 2014, 32 (Special Issue), 47-67.

Zebb, Barbara J and J Gayle Beck, "Worry versus anxiety: Is there really a difference?," Behavior modification, 1998, 22 (1), 45-61. 
Panel A. Intensity of worries

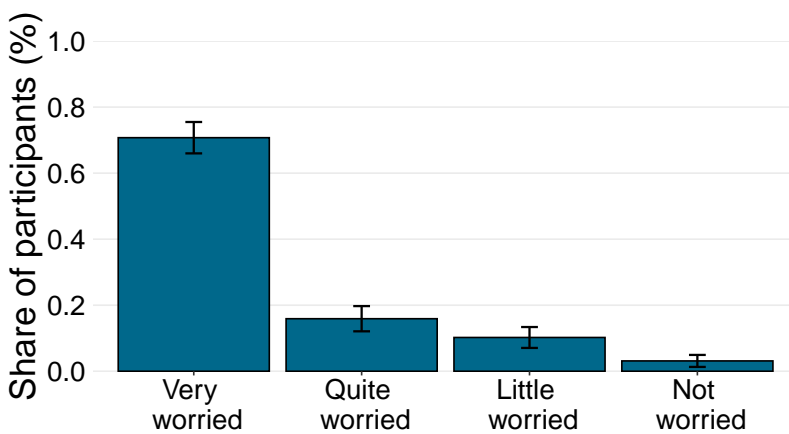

Panel C. Duration of worries

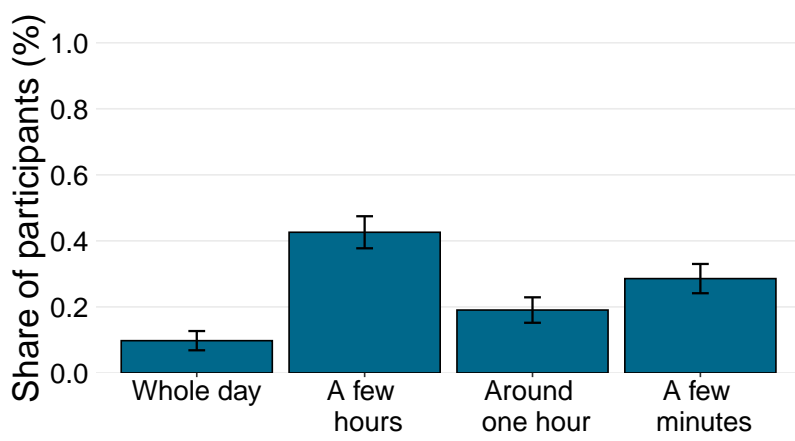

Panel B. Frequency of worries
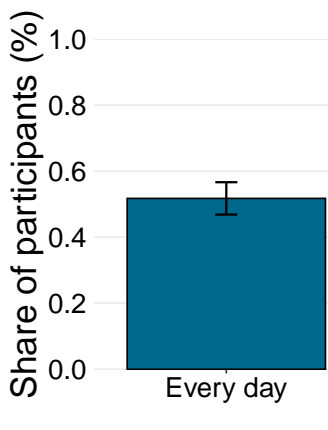

Every day

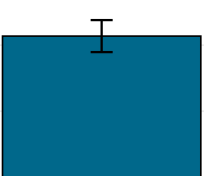

A few times a week
Not often

Panel D. Thoughts during work

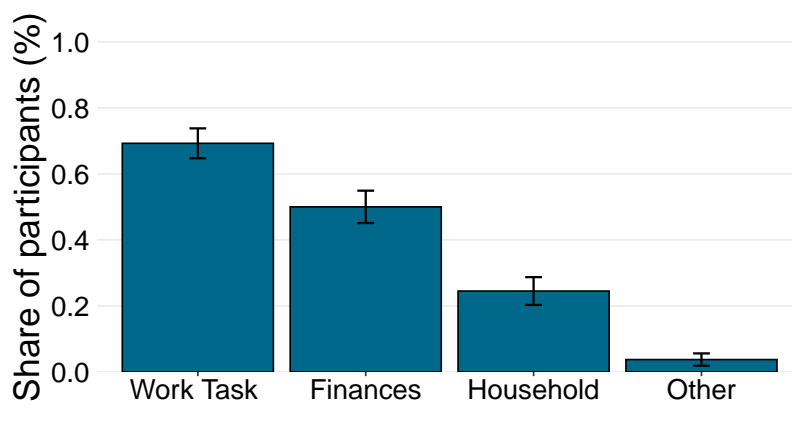

Panel E. Triggers of financial worries

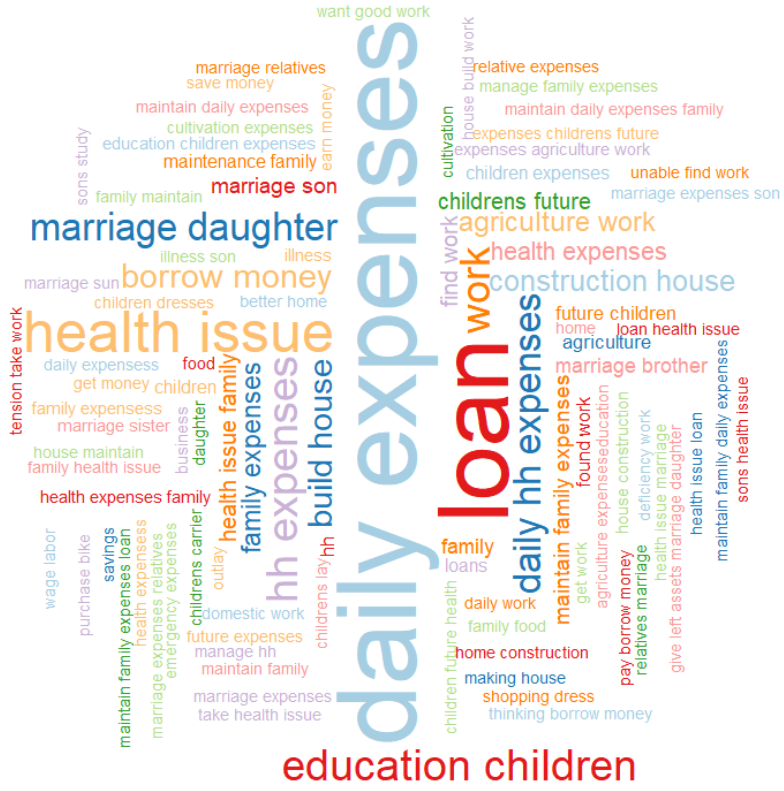

Notes: This figure shows the participants' responses to question related to financial worries and stressors.

- In Panels A to D, we show answers to four questions: (A) "How worried are you about your finances?" $(N=352)$; (B) "How often do you worry about your finances?" $(N=400) ;(\mathrm{C})$ "How long do you worry about finances every day?" ( $N=399)$; and (D) "What were you thinking about while working?" (unprompted question, $N=400$ ). Question (A) was asked during baseline, except in rounds 3 and 4. Questions (B) to (D) were asked during later surveys, so excludes those who were not present on those survey days.

- In Panel E, we show a word cloud representing answers to the question "What makes you worry about money issues?" $(N=402)$. The font size is proportional to the frequency of terms mentioned by participants. 


\section{CONTROL GROUP}

\begin{tabular}{|c|c|c|c|}
\hline First & Payment Schedule & & Remaining \\
\hline Payment & Announced & & Payment \\
\hline$\downarrow$ & & & $\downarrow$ \\
\hline Day 1 & Day 5 & Day 8 & Day 12 \\
\hline
\end{tabular}

\begin{tabular}{|c|}
\hline Baseline Period \\
\hline
\end{tabular}

\section{TREATMENT GROUP}

\begin{tabular}{|c|c|c|c|}
\hline First & Payment Schedule & Cash & Remaining \\
\hline Payment & Announced & Infusion & Payment \\
\hline Day 1 & Day 5 & Day 8 & $\begin{array}{c}\checkmark \\
\text { Day } 12\end{array}$ \\
\hline
\end{tabular}

Notes: This figure shows the experimental design of the study.

- The lower part of the figure shows the (early payment) treatment group. The upper part of the figure shows the corresponding control group.

- In the control group (upper part of the figure), workers were paid their training wage on day 1 , and received the rest of their accrued earnings on day 12.

- In the treatment group (lower part of the figure), workers were paid on their training wage on day 1 . They then received an early payment on day 8 , comprised of their accrued earnings from days 2 to 7 . They received the remainder of their accrued earnings on day 12.

- Within each round, all workers were cross-randomized to Wave A or Wave B. The payment schedule for Wave A workers is shown here. Wave B treatment workers were paid one day later, on day 9 (see Appendix Figure A.2 for detailed depiction).

- Within each of the treatment and control groups, workers were randomized to receive the priming intervention on day 6 , day 10 , or not at all for Wave A, and on days 7,11 , or not at all for Wave B. 
Figure 3: Treatment Effects of Early Pay Cash Infusion

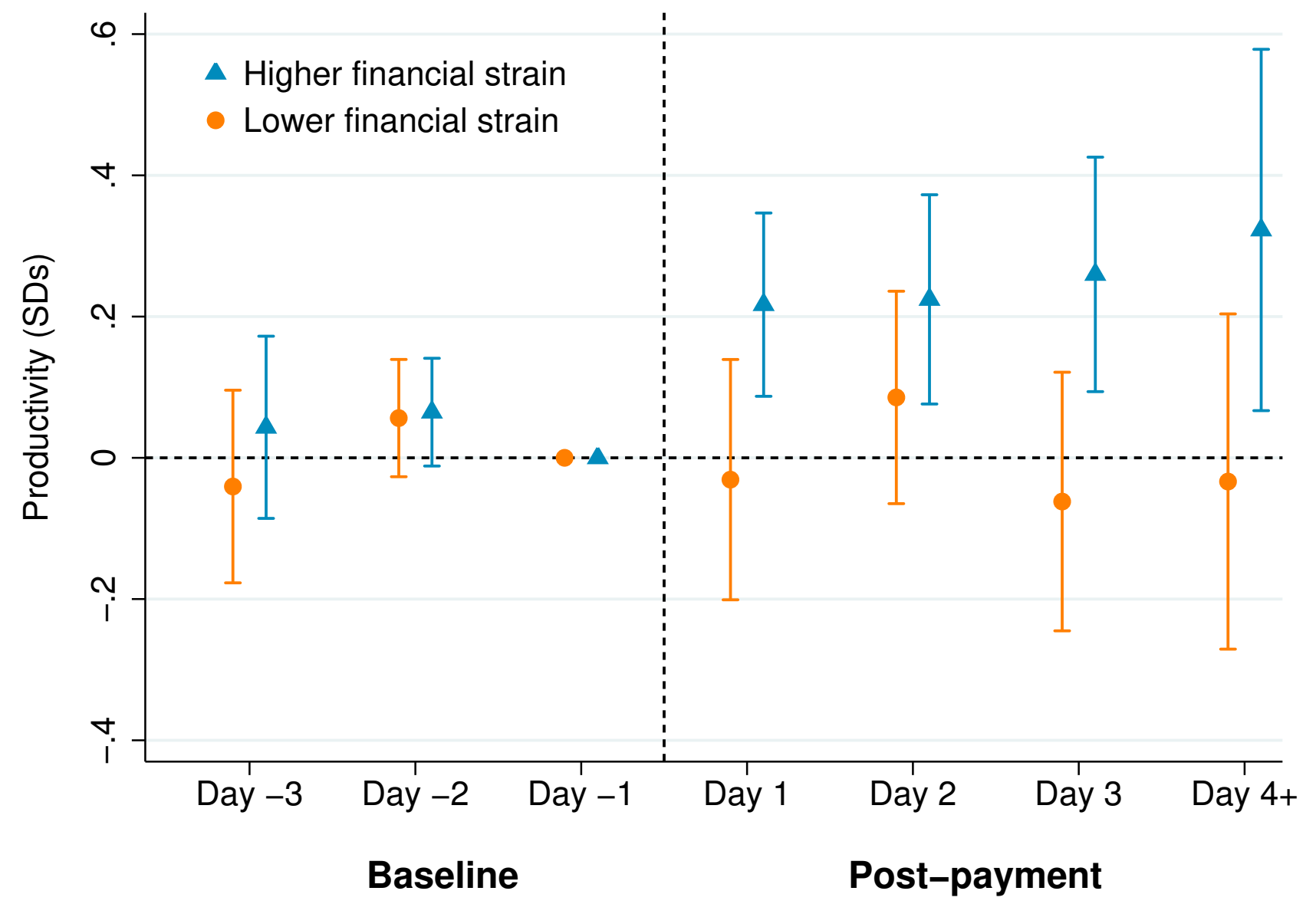

Notes: This figure plots estimated effects of early payment on output, comparing the treatment and control group, separately for workers with above and below median values of the financial strain index.

- The $\mathrm{x}$-axis indexes days so that Day 1 is the first day of the post-payment period (after cash is disbursed to treatment workers in a given wave). Day -1 is the last day of the baseline period (before treatment status is announced), and is the omitted time category in the regression. See Figure 2 for definitions of the Baseline and Post-payment periods.

- The financial strain index is an average of four binary measures: whether the individual reported owning farmland, living in a non-mud house, not having outstanding credits, and being able to come up with Rs. 1,000 easily in case of an emergency. Lower financial strain is an indicator that equals 1 if the worker has a below median level of financial strain by this index measure (i.e. above median index value).

- The regression controls for shorter production slot lengths, announcement, and priming, and control for worker, day, and round times hour-of-the-day fixed effects. Announcement controls include an indicator that equals 1 during the days after schedule announcement and before cash infusion, and also its interaction with being in the earlypay treatment group. Announcement controls are interacted with an indicator for lower financial strain. Priming controls include a dummy for all slots occurring after any priming intervention on that day, and its interaction with an indicator for whether a worker actually received a priming intervention on that day.

- Standard errors are clustered at the individual level. $95 \%$ confidence intervals are shown. 


\section{PANEL A: Overall Impacts}

\begin{tabular}{|c|c|c|c|c|}
\hline & \multicolumn{2}{|c|}{ Loans and Credits } & \multicolumn{2}{|c|}{ Expenditures } \\
\hline & $\begin{array}{c}\text { Any } \\
\text { Payment } \\
(1)\end{array}$ & $\begin{array}{c}\text { Amount } \\
(2)\end{array}$ & $\begin{array}{c}\text { Food } \\
(3)\end{array}$ & $\begin{array}{c}\text { All } \\
\text { Expenses } \\
(4)\end{array}$ \\
\hline Cash & $\begin{array}{c}0.40^{* * *} \\
(0.04)\end{array}$ & $\begin{array}{c}270.39^{* * *} \\
(51.59)\end{array}$ & $\begin{array}{c}67.44^{* * *} \\
(24.15)\end{array}$ & $\begin{array}{c}370.39^{* * *} \\
(68.18)\end{array}$ \\
\hline Control group mean & 0.18 & 94.20 & 269.94 & 572.54 \\
\hline $\mathrm{N}$ : workers & 402 & 402 & 402 & 402 \\
\hline
\end{tabular}

PANEL B: Heterogeneous Treatment Effects

\begin{tabular}{|c|c|c|c|c|}
\hline & \multirow{2}{*}{\multicolumn{2}{|c|}{ Loans and Credits }} & & \\
\hline & & & \multicolumn{2}{|c|}{ Expenditures } \\
\hline & $\begin{array}{c}\text { Any } \\
\text { Payment } \\
(1)\end{array}$ & $\begin{array}{c}\text { Amount } \\
(2)\end{array}$ & $\begin{array}{l}\text { Food } \\
(3)\end{array}$ & $\begin{array}{c}\text { All } \\
\text { Expenses } \\
(4)\end{array}$ \\
\hline Cash & $\begin{array}{c}0.53^{* * *} \\
(0.08)\end{array}$ & $\begin{array}{c}312.52^{\text {*** }} \\
(69.97)\end{array}$ & $\begin{array}{c}59.21 \\
(39.23)\end{array}$ & $\begin{array}{c}486.26^{* * *} \\
(115.95)\end{array}$ \\
\hline Cash $\times$ Lower financial strain & $\begin{array}{c}-0.33^{* *} \\
(0.16)\end{array}$ & $\begin{array}{l}-103.64 \\
(138.09)\end{array}$ & $\begin{array}{c}18.00 \\
(87.61)\end{array}$ & $\begin{array}{l}-289.20 \\
(249.11)\end{array}$ \\
\hline $\mathrm{N}$ : workers & 401 & 401 & 401 & 401 \\
\hline
\end{tabular}

Notes: This table presents the impact of the early-pay treatment on expenditure patterns. Regressions are at the worker level, comparing average differences in expenditures in the 3 days following the cash infusion among treatment vs. control workers.

- Panel A shows the overall impacts of the treatment. "Cash" refers to whether an individual is in the early-payment treatment group. The dependent variables in the first two columns are whether the participant made any repayments of loans or credits (Col. 1) and the overall amount of such payments (Col. 2).

- Panel B shows heterogeneous treatment effects by financial strain. "Lower financial strain" is a continuous measure of the worker's financial strain. This index is a simple average of four binary financial strain measures: whether the individual reported owning farmland, living in a non-mud house, not having outstanding credits, and being able to come up with Rs. 1,000 easily in case of an emergency. Higher index values correspond to lower financial strain. This index cannot be computed for one worker, who did not complete the baseline survey.

All regressions use survey responses from the end of the contract period. No baseline survey is available for these outcomes. All regressions control for round fixed effects and an indicator for shorter experimental periods. Robust standard errors are reported. 
Table 2: The Impact of the Cash Infusion on Worker Productivity

\section{PANEL A: Overall Impacts}

\section{Hourly Production Measure}

\begin{tabular}{lcccccc}
\cline { 5 - 6 } & \multicolumn{2}{c}{ Raw } & & \multicolumn{3}{c}{ Normalized } \\
\cline { 2 - 3 } \cline { 5 - 6 } & $(1)$ & & $(2)$ & $(3)$ & $(4)$ & $(5)$ \\
\hline Cash $\times$ Post-pay & $0.240^{* * *}$ & & $0.102^{* * *}$ & $0.115^{* *}$ & $0.115^{* *}$ & $0.114^{* *}$ \\
& $(0.088)$ & $(0.037)$ & $(0.058)$ & $(0.058)$ & $(0.058)$ \\
\hline Control group mean & 3.843 & 0.000 & 0.000 & 0.000 & 0.000 \\
Announcement controls & $\mathrm{N}$ & $\mathrm{N}$ & $\mathrm{Y}$ & $\mathrm{Y}$ & $\mathrm{Y}$ \\
Priming controls & $\mathrm{N}$ & $\mathrm{N}$ & $\mathrm{N}$ & $\mathrm{Y}$ & $\mathrm{Y}$ \\
Sample with baseline data only & $\mathrm{N}$ & $\mathrm{N}$ & $\mathrm{N}$ & $\mathrm{N}$ & $\mathrm{Y}$ \\
N: worker-hours & 22,849 & 22,849 & 22,849 & 22,849 & 22,789 \\
\hline
\end{tabular}

PANEL B: Heterogeneous Treatment Effects

PANEL B: Heterogeneous Treatment Efects

\begin{tabular}{|c|c|c|c|c|c|c|}
\hline & \multicolumn{2}{|c|}{ Financial Strain Index } & \multicolumn{2}{|c|}{ Asset Proxies } & \multicolumn{2}{|c|}{ Liquidity Proxies } \\
\hline & $\begin{array}{c}\text { Continuous } \\
\text { (1) }\end{array}$ & $\begin{array}{c}\text { Binary } \\
(2)\end{array}$ & $\begin{array}{c}\text { Owns land } \\
(3)\end{array}$ & $\begin{array}{c}\text { Non-mud } \\
\text { house } \\
(4)\end{array}$ & $\begin{array}{l}\text { No food } \\
\text { credits } \\
\quad(5)\end{array}$ & $\begin{array}{l}\text { Get } 1 \mathrm{k} \text { for } \\
\text { emergency } \\
(6)\end{array}$ \\
\hline Cash $\times$ Post-pay & $\begin{array}{c}0.253^{* * *} \\
(0.092)\end{array}$ & $\begin{array}{c}0.215^{* * *} \\
(0.079)\end{array}$ & $\begin{array}{c}0.218^{* * *} \\
(0.076)\end{array}$ & $\begin{array}{l}0.139^{* *} \\
(0.070)\end{array}$ & $\begin{array}{l}0.179^{* *} \\
(0.069)\end{array}$ & $\begin{array}{c}0.117 \\
(0.075)\end{array}$ \\
\hline $\begin{array}{l}\text { Cash } \times \text { Post-pay } \\
\quad \times \text { Lower financial strain }\end{array}$ & $\begin{array}{c}-0.365^{* *} \\
(0.175)\end{array}$ & $\begin{array}{r}-0.211^{*} \\
(0.117)\end{array}$ & $\begin{array}{l}-0.177 \\
(0.113)\end{array}$ & $\begin{array}{l}-0.133 \\
(0.110)\end{array}$ & $\begin{array}{l}-0.141 \\
(0.119)\end{array}$ & $\begin{array}{l}-0.048 \\
(0.111)\end{array}$ \\
\hline $\begin{array}{l}\text { P-val: cash effect }+ \text { interaction } \\
\text { N: worker-hours }\end{array}$ & 22,789 & $\begin{array}{c}0.965 \\
22,789\end{array}$ & $\begin{array}{c}0.625 \\
22,789\end{array}$ & $\begin{array}{c}0.945 \\
22,789\end{array}$ & $\begin{array}{c}0.695 \\
22,789\end{array}$ & $\begin{array}{c}0.397 \\
22,789\end{array}$ \\
\hline
\end{tabular}

Notes: This table shows the impact of the early-payment treatment on worker productivity.

- Panel A presents average treatment effects across workers. "Cash" refers to whether an individual is in the earlypayment treatment group. "Post-pay" indicates the period after cash infusion. The dependent variable in Col. 1 is the hourly (raw) number of accepted leaf plates produced by each worker. The remaining columns use normalized versions of this variable. The specification in Col. 4 corresponds to regression equation 1 in Section 4.2. Col. 3 estimates this equation without priming controls, and Cols. 1-2 also remove the announcement controls, so that both the Baseline and Announcement periods are pooled as the omitted (baseline) time category. Col. 5 restricts the sample to the workers who answered the baseline survey (i.e. for whom we have data on financial strain), and therefore omits 1 worker from the sample. All regressions control for worker, day, and round times hour-of-the-day fixed effects, as well as dummies for shorter production slot lengths. Announcement controls include an indicator that equals 1 on the days during the announcement period, and also its interaction with "Cash". Standard errors in both panels are clustered by worker.

- Panel B shows heterogeneous treatment effects by financial strain. Regressions correspond to the Panel A Col. 5 specification, but add interactions with a proxy for lower financial strain. Column headings indicate which proxy for financial strain is used in regressions. The financial strain index is a simple average of the four binary proxies in Cols. 3 to 6 . Higher values of the index correspond to lower financial strain. Col. 1 uses the continuous version of this index; Col. 2 uses an indicator that equals 1 if the worker has a below median level of financial strain (i.e. above median index value). 
Table 3: The Impact of the Cash Infusion on Attentiveness

\begin{tabular}{|c|c|c|c|c|c|c|c|c|}
\hline & \multicolumn{4}{|c|}{ Attentiveness index } & \multicolumn{4}{|c|}{ High attentiveness } \\
\hline & $(1)$ & $(2)$ & $(3)$ & $(4)$ & $(5)$ & $(6)$ & $(7)$ & $(8)$ \\
\hline Cash $\times$ Post-pay & $\begin{array}{c}0.080^{* *} \\
(0.037)\end{array}$ & $\begin{array}{c}0.087 \\
(0.061)\end{array}$ & $\begin{array}{l}0.274^{* *} \\
(0.107)\end{array}$ & $\begin{array}{c}0.229^{* * *} \\
(0.086)\end{array}$ & $\begin{array}{c}0.077^{* * *} \\
(0.025)\end{array}$ & $\begin{array}{l}0.097^{* *} \\
(0.038)\end{array}$ & $\begin{array}{c}0.200^{* * *} \\
(0.070)\end{array}$ & $\begin{array}{c}0.186^{* * *} \\
(0.055)\end{array}$ \\
\hline Cash $\times$ Post-pay $\times$ Lower financial strain & & & $\begin{array}{c}-0.493^{* *} \\
(0.226) \\
\end{array}$ & $\begin{array}{c}-0.287^{* *} \\
(0.122) \\
\end{array}$ & & & $\begin{array}{c}-0.276^{* *} \\
(0.139) \\
\end{array}$ & $\begin{array}{c}-0.185^{* *} \\
(0.075) \\
\end{array}$ \\
\hline $\begin{array}{l}\text { Announcement controls } \\
\text { Financial strain index } \\
\text { P-val: cash effect }+ \text { interaction } \\
\text { N: worker-hours }\end{array}$ & 15,265 & 15,265 & $\begin{array}{c}\mathrm{Y} \\
\text { Continuous } \\
15,227\end{array}$ & $\begin{array}{c}\mathrm{Y} \\
\text { Binary } \\
0.513 \\
15,227\end{array}$ & 15,265 & $\begin{array}{c}\mathrm{Y} \\
15,265\end{array}$ & $\begin{array}{l}\text { Y } \\
\text { Continuous } \\
15,227\end{array}$ & $\begin{array}{c}\mathrm{Y} \\
\text { Binary } \\
0.985 \\
15,227\end{array}$ \\
\hline
\end{tabular}

Notes: This table shows the impact of the early-payment treatment on attentiveness.

- The attentiveness index is an average of three proxies for attentiveness: the average number of leaves, stitches, and double holes (each of which signifies that a stitch was removed in order to correct a mistake) per plate during the production hour slot. The three measures are normalized using the control group's production (mean and standard deviation) in the post-pay period. We then take a simple average to create the attentiveness index, with the scale reversed (multiplied by -1) so that a higher value on the index corresponds to improved attentiveness. "High attentiveness" indicates that the index value is greater than the sample median.

- The dependent variable is the continuous attentiveness index in Cols. 1 through 4 , and the high attentiveness indicator variable in Cols. 5 through 8. "Cash" is a binary indicator that equals 1 if an individual is in the early-payment treatment group. "Post-pay" indicates the period after cash infusion.

- The financial strain index is a simple average of four binary proxies reflecting workers' assets and liquidity (see Section 4.1 and Table 2). Higher values of the index reflect lower financial strain. Cols. 3 and 7 examine heterogeneity using the continuous index measure. Cols. 4 and 8 examine heterogeneity using binary indicator that equals 1 if the worker has a below median level of financial strain (i.e. above median index value).

- Regressions in Cols. 2-4 and 6-8 include standard controls: worker, day, and round times hour-of-the-day fixed effects, as well as announcement controls, priming controls, and dummies for shorter production slot lengths. Announcement controls include an indicator that equals 1 on the days during the announcement period, and also its interaction with "Cash". Regressions in Cols. 1 and 5 exclude announcement controls so that both the Baseline and Announcement periods are pooled as the omitted (baseline) time category. Standard errors are clustered by worker. 
Table 4: Impact of Piece Rate Variation on Worker Productivity and Attentiveness

\begin{tabular}{|c|c|c|c|c|c|}
\hline & \multicolumn{2}{|c|}{ Hourly production } & \multicolumn{2}{|c|}{ Attentiveness index } & \multirow{2}{*}{$\frac{\text { Attendance }}{(5)}$} \\
\hline & (1) & $(2)$ & $(3)$ & $(4)$ & \\
\hline Piece rate & $\begin{array}{l}0.018^{* *} \\
(0.008)\end{array}$ & & $\begin{array}{l}-0.008 \\
(0.009)\end{array}$ & & $\begin{array}{c}0.000 \\
(0.006)\end{array}$ \\
\hline Piece rate $=$ Rs. 3 & & $\begin{array}{c}0.021 \\
(0.015)\end{array}$ & & $\begin{array}{c}0.002 \\
(0.023)\end{array}$ & \\
\hline Piece rate $=$ Rs. 4 & & $\begin{array}{l}0.036^{* *} \\
(0.016)\end{array}$ & & $\begin{array}{l}-0.015 \\
(0.019)\end{array}$ & \\
\hline $\begin{array}{l}\text { Include absent workers } \\
\text { P-val: equality of coefficients }\end{array}$ & $\mathrm{N}$ & $\mathrm{N}$ & $\mathrm{N}$ & $\mathrm{N}$ & $\mathrm{Y}$ \\
\hline $\begin{array}{l}\text { Piece rate in }(1) \text { and }(3) \\
\text { Piece rate }=\text { Rs. } 3 \text { in (2) and (4) } \\
\text { Piece rate }=\text { Rs. } 4 \text { in (2) and (4) }\end{array}$ & 0.004 & $\begin{array}{l}0.345 \\
0.004\end{array}$ & & & \\
\hline $\begin{array}{l}\mathrm{N} \text { : worker-hours } \\
\mathrm{N} \text { : worker-days }\end{array}$ & 4,374 & 4,374 & 4,373 & 4,373 & 904 \\
\hline
\end{tabular}

Notes: This table shows the impact of changing piece-rates on worker productivity, attentiveness, and attendance. The observations come from supplementary rounds (without the early-pay treatment) with 151 workers.

- The dependent variables are normalized hourly production in Cols. 1-2, the attentiveness index in Cols. 3-4, and attendance in Col. 5. The attentiveness index is an average of three normalized proxies for attentiveness: the average number of leaves, stitches, and double holes (which signify that a stitch was removed in order to correct mistake) per plate during the production hour slot. The production and attentiveness measures are normalized using the same control group mean and standard deviations as the measures in the main rounds. Attendance is a day-level variable indicating whether worker was present at the work site.

- The piece-rate wage was randomized to be either Rs. 2, 3, or 4, so the omitted category in Cols. 2 and 4 is a piece-rate wage of Rs. 2.

- Regressions in Cols. 1-4 control for individual, day, and round times hour-of-the-day fixed effects, and also include indicators for shorter production slot lengths. The regression in Col. 5 controls for individual and day fixed effects. Standard errors are clustered by worker. 
Table 5: Announcement Effects, Fairness, and Trust

\begin{tabular}{|c|c|c|c|c|c|c|}
\hline & \multicolumn{6}{|c|}{ Hourly Production } \\
\hline & $(1)$ & $(2)$ & (3) & (4) & $(5)$ & (6) \\
\hline Cash $\times 1$ day post announcement & $\begin{array}{l}-0.031 \\
(0.034)\end{array}$ & $\begin{array}{l}-0.027 \\
(0.035)\end{array}$ & $\begin{array}{l}-0.058 \\
(0.044)\end{array}$ & & & \\
\hline Cash $\times 2$ days post announcement & $\begin{array}{c}0.005 \\
(0.044)\end{array}$ & $\begin{array}{c}0.011 \\
(0.045)\end{array}$ & $\begin{array}{c}0.030 \\
(0.045)\end{array}$ & & & \\
\hline Cash $\times 1$ day post announcement $\times$ Lower financial strain & & & $\begin{array}{c}0.053 \\
(0.059)\end{array}$ & & & \\
\hline Cash $\times 2$ days post announcement $\times$ Lower financial strain & & & $\begin{array}{l}-0.041 \\
(0.050)\end{array}$ & & & \\
\hline Cash $\times$ Announcement period & & & & $\begin{array}{c}0.006 \\
(0.040)\end{array}$ & $\begin{array}{c}0.008 \\
(0.041)\end{array}$ & $\begin{array}{c}0.007 \\
(0.041)\end{array}$ \\
\hline Cash $\times$ Payment day & $\begin{array}{c}0.067 \\
(0.053)\end{array}$ & $\begin{array}{c}0.074 \\
(0.055)\end{array}$ & $\begin{array}{c}0.073 \\
(0.055)\end{array}$ & $\begin{array}{c}0.095 \\
(0.067)\end{array}$ & $\begin{array}{c}0.093 \\
(0.063)\end{array}$ & $\begin{array}{l}0.120^{*} \\
(0.061)\end{array}$ \\
\hline Cash $\times$ Payment day $\times$ Wave $B$ & & & & $\begin{array}{l}-0.062 \\
(0.069)\end{array}$ & $\begin{array}{l}-0.029 \\
(0.054)\end{array}$ & $\begin{array}{l}-0.069 \\
(0.074)\end{array}$ \\
\hline Cash $\times$ Payment day $\times$ Lower financial strain & & & & & & $\begin{array}{l}-0.014 \\
(0.074)\end{array}$ \\
\hline Cash $\times$ Payment day $\times$ Wave $B \times$ Lower financial strain & & & & & & $\begin{array}{c}0.040 \\
(0.108)\end{array}$ \\
\hline Cash $\times$ Post-pay & & $\begin{array}{l}0.117^{* *} \\
(0.059)\end{array}$ & $\begin{array}{c}0.113^{*} \\
(0.059) \\
\end{array}$ & & $\begin{array}{l}0.118^{* *} \\
(0.059) \\
\end{array}$ & $\begin{array}{l}0.117^{* *} \\
(0.059)\end{array}$ \\
\hline Post-payment period & No & Yes & Yes & No & Yes & Yes \\
\hline N: worker-hours & 15207 & 22849 & 22789 & 15207 & 22849 & 22789 \\
\hline
\end{tabular}

Notes: This table shows productivity in the treatment and control group after announcement and on the payment day (before payment in the evening).

- "Cash" is an indicator that equals 1 if an individual is in the early-payment treatment group. In Cols. 1-3, 1 day post announcement is an indicator that equals 1 on the day the pay announcement was made (i.e. corresponding to day 5 , the day the announcement is made in the morning), and 2 days post announcement is an indicator that equals 1 the day after that. "Payment day" is an indicator that equals 1 on the day when early payment occurred for a given worker's wave (i.e. day 8 for Wave A workers and day 9 for Wave B workers). Cash payments were made in the evening after work on these days, so "Cash $\times$ Payment day" captures effects during the workday before the evening payment was made to treatment workers.

- Cols. 1-3 also include an indicator for 3+ days post announcement (which absorbs any additional announcement days for rounds with longer announcement periods, and equals 1 for days that were 3 days or more post announcement, but before the payment day) interacted with Cash. "Post-pay" is an indicator for the Post-payment period for the worker's wave (after early cash payments have been disbursed).

- In Cols. 4-6, "Announcement period" is an indicator that equals 1 for all days during the announcement period (post announcement, before pay), excluding the payment day. "Wave B" is a dummy indicating that participants are assigned to Wave B (see Section 3.4 and Figure A.2 for details). "Lower financial strain" is a binary indicator that equals 1 if the worker has a below median level of financial strain (i.e. above median index value). Cols. 1 and 4 restrict the sample to exclude the post-payment period; the remaining columns include the full sample. All regressions include worker, day, and round times hour-of-the-day fixed effects, priming controls, and dummies for shorter production slot lengths. Standard errors are clustered by worker. 
Table 6: Tests for Nutrition Channels

\begin{tabular}{|c|c|c|c|c|c|c|c|c|c|}
\hline & \multicolumn{5}{|c|}{ Breakfast Measures } & \multicolumn{4}{|c|}{ Hourly Production } \\
\hline & $\begin{array}{c}\text { Had } \\
\text { any } \\
\text { break- } \\
\text { fast } \\
(1)\end{array}$ & $\begin{array}{l}\text { Ate rice } \\
\quad(2)\end{array}$ & $\begin{array}{l}\text { Amount } \\
\text { of rice } \\
(3)\end{array}$ & $\begin{array}{c}\text { Ate veg- } \\
\text { etables } \\
(4)\end{array}$ & $\begin{array}{c}\text { Ate any } \\
\text { other } \\
\text { item } \\
(5)\end{array}$ & $(6)$ & (7) & (8) & (9) \\
\hline Cash & $\begin{array}{l}-0.007 \\
(0.013)\end{array}$ & $\begin{array}{l}-0.002 \\
(0.025)\end{array}$ & $\begin{array}{l}-3.889 \\
(7.154)\end{array}$ & $\begin{array}{l}-0.021 \\
(0.041)\end{array}$ & $\begin{array}{c}0.057 \\
(0.043)\end{array}$ & & & & \\
\hline Cash $\times$ Post-pay & & & & & & $\begin{array}{l}0.109^{*} \\
(0.065)\end{array}$ & $\begin{array}{c}0.263^{* * *} \\
(0.092)\end{array}$ & $\begin{array}{l}0.112^{*} \\
(0.060)\end{array}$ & $\begin{array}{c}0.112^{*} \\
(0.058)\end{array}$ \\
\hline Cash $\times$ Post-pay $\times$ Hour of day & & & & & & $\begin{array}{c}0.003 \\
(0.007)\end{array}$ & $\begin{array}{l}-0.011 \\
(0.012)\end{array}$ & & \\
\hline Cash $\times$ Post-pay $\times$ Lower financial strain & & & & & & & $\begin{array}{c}-0.301^{* *} \\
(0.133)\end{array}$ & & \\
\hline Cash $\times$ Post-pay $\times$ Hour of day $\times$ Lower financial strain & & & & & & & $\begin{array}{c}0.023 \\
(0.015)\end{array}$ & & \\
\hline Cash $\times$ Post-pay $\times$ Last 2 hours of day & & & & & & & & $\begin{array}{c}0.004 \\
(0.024)\end{array}$ & \\
\hline Cash $\times$ Post-pay $\times$ Last 1 hour of day & & & & & & & & & $\begin{array}{c}0.019 \\
(0.032)\end{array}$ \\
\hline Control group mean & 0.98 & 0.94 & 180.63 & 0.76 & 0.27 & & & & \\
\hline $\mathrm{N}$ : workers & 320 & 320 & 320 & 320 & 320 & & & & \\
\hline p-value: cash effect + interaction & & & & & & & & 0.04 & 0.05 \\
\hline N: worker-hours & & & & & & 22,849 & 22,789 & 22,849 & 22,849 \\
\hline
\end{tabular}

Notes: This table shows the impact of the early-payment treatment on breakfast consumption following the cash infusion (Cols. 1-5) and on worker productivity changes throughout the day in the post-payment period (Cols. 6-9).

- Cols. 1-5 present worker-level regressions where the dependent variables are breakfast measures averaged across the 2 mornings following the early cash payment day for each wave. "Cash" is an indicator that equals 1 if an individual is in the early-payment treatment group. Regressions control for round fixed effects and an indicator for shorter rounds. Robust standard errors are reported.

- In Cols. 6-9, the dependent variable is normalized hourly output. "Post-pay" is an indicator that equals 1 on the days during the Post-payment period for the worker's wave. "Hour of day" is a linear control for the work hour within a production day. "Last 1 (2) hour(s) of day" is an indicator for the last one (two) production hours in a day (for rounds with 5-hour schedules) or post-lunch production (for rounds with 7-hour schedules). "Lower financial strain" is an indicator equals 1 if the worker has a below median level of financial strain (i.e. above median index value).

- Regressions in Cols. 6-9 include controls for worker, day, and round times hour-of-the-day fixed effects, as well as announcement controls, priming controls, and dummies for shorter production slot lengths. Standard errors are clustered by worker. 


\section{A Online Appendix}

\section{A.1 Appendix Figures and Tables}

Figure A.1: Leaf Plate

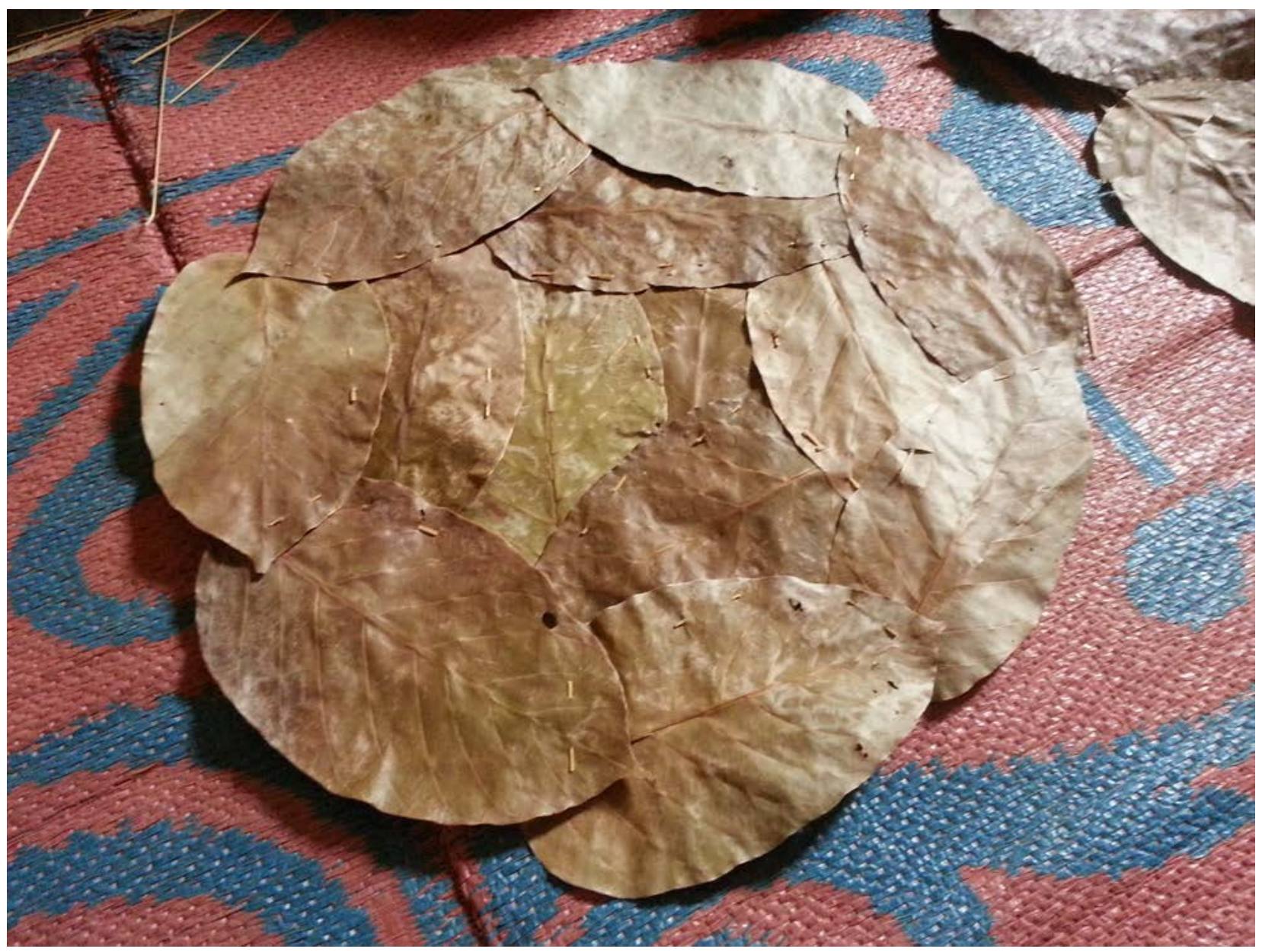

Notes: This figure shows a sal tree leaf plate akin to the ones produced by workers in the experiment. The backside of the plate is shown. In accordance with quality standards set by partnering contractors, leaf plates were required to (i) meet a minimum size requirement, (ii) have no gaping holes, (iii) have all leafstalks (petioles) covered by other leaves, and (iv) have the inner center parts placed underneath the outer rings of the plates. 
Figure A.2: Experimental Design - Detailed Timeline

CONTROL GROUP WAVE A

$\underbrace{\text { Day } 1}_{\text {Baseline Period }} \underbrace{\begin{array}{c}\text { Payment Schedule } \\ \text { Announced }\end{array}}_{\text {Announcement Period }}$

CONTROL GROUP WAVE B

\begin{tabular}{|c|c|c|c|}
\hline First & Payment Schedule & & Remaining \\
\hline Payment & Announced & & Payment \\
\hline $\begin{array}{c}\checkmark \\
\text { Day } 1\end{array}$ & Day 5 & Day 9 & $\begin{array}{c}\downarrow \\
\text { Day } 12\end{array}$ \\
\hline
\end{tabular}

TREATMENT GROUP WAVE A

\begin{tabular}{|c|c|c|c|}
\hline First & Payment Schedule & Cash & Remaining \\
\hline Payment & Announced & Infusion & Payment \\
\hline$\downarrow$ & $\downarrow$ & $\downarrow$ & $\downarrow$ \\
\hline Day 1 & Day 5 & Day 8 & Day 12 \\
\hline
\end{tabular}

TREATMENT GROUP WAVE B

$\underbrace{\text { Day } \mathbf{1}}_{\text {Baseline Period }} \underbrace{\begin{array}{c}\text { First } \\ \text { Payment }\end{array}}_{\text {Announcement Period }} \underbrace{\substack{\text { Payment Schedule } \\ \text { Announced }}}_{\text {Post-Pay Period - Treatment Wave B }}$

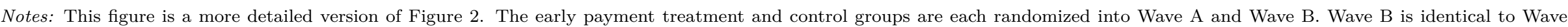

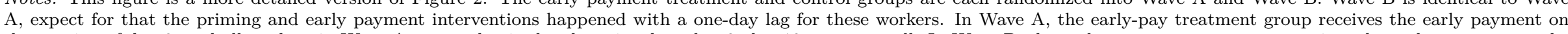

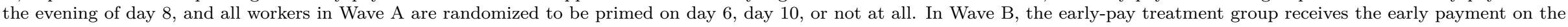
evening of day 9 , and all workers in Wave B are randomized to be primed on day 7 , day 11 , or not at al 
Table A1: Sample Characteristics and Tests for Baseline Balance

\begin{tabular}{|c|c|c|c|c|c|c|}
\hline & \multicolumn{2}{|c|}{ All Sample } & \multicolumn{2}{|c|}{ Below median strain } & \multicolumn{2}{|c|}{ Above median strain } \\
\hline & $\begin{array}{c}\text { Control } \\
\text { mean } \\
(1)\end{array}$ & $\begin{array}{c}\text { Coef. on } \\
\text { Cash } \\
(2)\end{array}$ & $\begin{array}{c}\text { Control } \\
\text { mean } \\
(3)\end{array}$ & $\begin{array}{c}\text { Coef. on } \\
\text { Cash } \\
(4)\end{array}$ & $\begin{array}{c}\text { Control } \\
\text { mean } \\
(5)\end{array}$ & $\begin{array}{l}\text { Coef. on } \\
\text { Cash } \\
(6)\end{array}$ \\
\hline \multicolumn{7}{|c|}{ Panel A. Demographics, Labor, and Wealth } \\
\hline Age & $\begin{array}{l}39.19 \\
{[8.86]}\end{array}$ & $\begin{array}{c}-0.51 \\
(0.84)\end{array}$ & $\begin{array}{l}38.76 \\
{[9.15]}\end{array}$ & $\begin{array}{c}-0.43 \\
(1.18)\end{array}$ & $\begin{array}{l}39.73 \\
{[8.50]}\end{array}$ & $\begin{array}{c}-0.71 \\
(1.19)\end{array}$ \\
\hline Years of education & $\begin{array}{c}4.69 \\
{[3.47]}\end{array}$ & $\begin{array}{c}-0.04 \\
(0.33)\end{array}$ & $\begin{array}{c}5.01 \\
{[3.48]}\end{array}$ & $\begin{array}{l}-0.41 \\
(0.45)\end{array}$ & $\begin{array}{c}4.33 \\
{[3.47]}\end{array}$ & $\begin{array}{c}0.15 \\
(0.49)\end{array}$ \\
\hline Can read newspaper in Odiya & $\begin{array}{c}0.63 \\
{[0.48]}\end{array}$ & $\begin{array}{c}0.02 \\
(0.05)\end{array}$ & $\begin{array}{c}0.68 \\
{[0.47]}\end{array}$ & $\begin{array}{c}-0.03 \\
(0.06)\end{array}$ & $\begin{array}{c}0.56 \\
{[0.50]}\end{array}$ & $\begin{array}{c}0.01 \\
(0.07)\end{array}$ \\
\hline Primarily daily laborer & $\begin{array}{c}0.75 \\
{[0.43]}\end{array}$ & $\begin{array}{c}-0.05 \\
(0.04)\end{array}$ & $\begin{array}{c}0.70 \\
{[0.46]}\end{array}$ & $\begin{array}{c}-0.08 \\
(0.06)\end{array}$ & $\begin{array}{c}0.81 \\
{[0.39]}\end{array}$ & $\begin{array}{l}-0.03 \\
(0.07)\end{array}$ \\
\hline Days of paid work in past 7 days & $\begin{array}{c}1.88 \\
{[2.12]}\end{array}$ & $\begin{array}{l}-0.16 \\
(0.19)\end{array}$ & $\begin{array}{c}1.84 \\
{[2.03]}\end{array}$ & $\begin{array}{c}-0.25 \\
(0.26)\end{array}$ & $\begin{array}{c}1.94 \\
{[2.25]}\end{array}$ & $\begin{array}{l}-0.12 \\
(0.31)\end{array}$ \\
\hline Days of paid work in past 30 days & $\begin{array}{c}8.60 \\
{[6.31]}\end{array}$ & $\begin{array}{c}0.10 \\
(0.70)\end{array}$ & $\begin{array}{c}8.99 \\
{[6.44]}\end{array}$ & $\begin{array}{c}-0.23 \\
(0.92)\end{array}$ & $\begin{array}{c}8.10 \\
{[6.14]}\end{array}$ & $\begin{array}{c}0.85 \\
(1.06)\end{array}$ \\
\hline $\begin{array}{l}\text { Lower financial strain (continu- } \\
\text { ous) }\end{array}$ & $\begin{array}{l}0.41 \\
{[0.25]}\end{array}$ & $\begin{array}{l}-0.00 \\
(0.03)\end{array}$ & $\begin{array}{l}0.59 \\
{[0.14]}\end{array}$ & $\begin{array}{c}0.03 \\
(0.02)\end{array}$ & $\begin{array}{l}0.17 \\
{[0.12]}\end{array}$ & $\begin{array}{l}-0.01 \\
(0.02)\end{array}$ \\
\hline Owns farmland & $\begin{array}{c}0.57 \\
{[0.50]}\end{array}$ & $\begin{array}{c}0.01 \\
(0.05)\end{array}$ & $\begin{array}{c}0.80 \\
{[0.40]}\end{array}$ & $\begin{array}{l}-0.01 \\
(0.05)\end{array}$ & $\begin{array}{c}0.26 \\
{[0.44]}\end{array}$ & $\begin{array}{l}0.11^{*} \\
(0.06)\end{array}$ \\
\hline Non-mud house & $\begin{array}{c}0.24 \\
{[0.43]}\end{array}$ & $\begin{array}{c}0.00 \\
(0.04)\end{array}$ & $\begin{array}{c}0.37 \\
{[0.48]}\end{array}$ & $\begin{array}{c}0.07 \\
(0.06)\end{array}$ & $\begin{array}{c}0.07 \\
{[0.27]}\end{array}$ & $\begin{array}{l}-0.05 \\
(0.03)\end{array}$ \\
\hline No outstanding credits & $\begin{array}{c}0.46 \\
{[0.50]}\end{array}$ & $\begin{array}{l}-0.00 \\
(0.05)\end{array}$ & $\begin{array}{c}0.64 \\
{[0.48]}\end{array}$ & $\begin{array}{c}0.06 \\
(0.06)\end{array}$ & $\begin{array}{c}0.23 \\
{[0.42]}\end{array}$ & $\begin{array}{l}-0.04 \\
(0.07)\end{array}$ \\
\hline Can get Rs. $1 \mathrm{~K}$ in emergency & $\begin{array}{c}0.36 \\
{[0.48]}\end{array}$ & $\begin{array}{l}-0.04 \\
(0.05)\end{array}$ & $\begin{array}{c}0.55 \\
{[0.50]}\end{array}$ & $\begin{array}{l}-0.01 \\
(0.07)\end{array}$ & $\begin{array}{c}0.11 \\
{[0.32]}\end{array}$ & $\begin{array}{l}-0.07 \\
(0.05)\end{array}$ \\
\hline \multicolumn{7}{|c|}{ Panel B. Financial Worries and Loans } \\
\hline Very worried about finances & $\begin{array}{c}0.69 \\
{[0.46]}\end{array}$ & $\begin{array}{c}0.03 \\
(0.05)\end{array}$ & $\begin{array}{c}0.66 \\
{[0.48]}\end{array}$ & $\begin{array}{l}-0.02 \\
(0.07)\end{array}$ & $\begin{array}{c}0.73 \\
{[0.45]}\end{array}$ & $\begin{array}{c}0.10 \\
(0.07)\end{array}$ \\
\hline Very worried about any loan & $\begin{array}{c}0.41 \\
{[0.49]}\end{array}$ & $\begin{array}{l}-0.02 \\
(0.05)\end{array}$ & $\begin{array}{c}0.39 \\
{[0.49]}\end{array}$ & $\begin{array}{l}-0.01 \\
(0.06)\end{array}$ & $\begin{array}{c}0.42 \\
{[0.50]}\end{array}$ & $\begin{array}{c}0.02 \\
(0.08)\end{array}$ \\
\hline $\begin{array}{l}\text { Amount of loans very worried } \\
\text { about }\end{array}$ & $\begin{array}{c}6,574 \\
{[12,645]}\end{array}$ & $\begin{array}{c}96 \\
(1,547)\end{array}$ & $\begin{array}{c}6,855 \\
{[13,943]}\end{array}$ & $\begin{array}{c}318 \\
(2,134)\end{array}$ & $\begin{array}{c}5,786 \\
{[10,795]}\end{array}$ & $\begin{array}{c}199 \\
(1,887)\end{array}$ \\
\hline Has loans & $\begin{array}{c}0.68 \\
{[0.47]}\end{array}$ & $\begin{array}{l}0.03 \\
(0.04)\end{array}$ & $\begin{array}{l}0.69 \\
{[0.46]}\end{array}$ & $\begin{array}{l}0.03 \\
(0.06)\end{array}$ & $\begin{array}{c}0.66 \\
{[0.48]}\end{array}$ & $\begin{array}{l}0.03 \\
(0.07)\end{array}$ \\
\hline Has moneylender loans & $\begin{array}{c}0.17 \\
{[0.38]}\end{array}$ & $\begin{array}{l}-0.02 \\
(0.04)\end{array}$ & $\begin{array}{l}0.15 \\
{[0.36]}\end{array}$ & $\begin{array}{c}0.02 \\
(0.05)\end{array}$ & $\begin{array}{c}0.21 \\
{[0.41]}\end{array}$ & $\begin{array}{l}-0.05 \\
(0.06)\end{array}$ \\
\hline \multicolumn{7}{|c|}{ Panel C. Baseline Attendance and Productivity } \\
\hline Attendance & $\begin{array}{c}0.97 \\
{[0.11]}\end{array}$ & $\begin{array}{c}0.01 \\
(0.01)\end{array}$ & $\begin{array}{c}0.97 \\
{[0.13]}\end{array}$ & $\begin{array}{c}0.02 \\
(0.02)\end{array}$ & $\begin{array}{c}0.98 \\
{[0.08]}\end{array}$ & $\begin{array}{l}-0.00 \\
(0.01)\end{array}$ \\
\hline Productivity & $\begin{array}{l}2.78 \\
{[1.46]}\end{array}$ & $\begin{array}{c}0.10 \\
(0.11)\end{array}$ & $\begin{array}{l}2.76 \\
{[1.61]}\end{array}$ & $\begin{array}{c}0.13 \\
(0.16)\end{array}$ & $\begin{array}{c}2.77 \\
{[1.26]}\end{array}$ & $\begin{array}{c}0.02 \\
(0.16)\end{array}$ \\
\hline Attentiveness index (continuous) & $\begin{array}{l}-0.23 \\
{[0.68]}\end{array}$ & $\begin{array}{l}-0.00 \\
(0.07)\end{array}$ & $\begin{array}{l}-0.30 \\
{[0.71]}\end{array}$ & $\begin{array}{c}0.04 \\
(0.11)\end{array}$ & $\begin{array}{l}-0.16 \\
{[0.65]}\end{array}$ & $\begin{array}{l}-0.05 \\
(0.09)\end{array}$ \\
\hline $\mathrm{N}$ : workers (Control or Cash) & 183 & 224 & 102 & 109 & 81 & 115 \\
\hline
\end{tabular}

Notes: This table reports baseline worker characteristics for the control group and tests for baseline differences between the control group and the (early pay) treatment group. Cols. 1, 3, and 5 show the average value and standard deviation of each variable for the control group. Cols. 2,4 , and 6 show the coefficient of a regression at the worker-level of each variable on a treatment indicator and round fixed effects with robust standard errors. All variables are either baseline characteristics or averages of participants' performance measures before payment schedules are announced. To generate the financial strain index, we take a simple average of the last four binary variables in Panel A. Recall that high index values indicate low financial strain. To generate the attentiveness index, we normalize each of the three measures of attentiveness (i.e. number of double holes, leaves, or stitches) using the control group's post-pay performance for each measure and take a simple average, with the scale reversed so that a higher value on the index corresponds to improved attentiveness. Appendix Table A2 reports additional balance tests. 
Table A2: More Detailed Sample Characteristics and Baseline Balance across Experimental Arms

\begin{tabular}{|c|c|c|c|c|c|c|c|c|c|}
\hline & \multicolumn{3}{|c|}{ Early-Pay Treatment } & \multicolumn{6}{|c|}{ Priming Treatment } \\
\hline & $\begin{array}{l}\text { Control } \\
\text { (1) }\end{array}$ & $\begin{array}{c}\text { Treatment } \\
(2)\end{array}$ & $\begin{array}{c}1=2 \\
(3)\end{array}$ & $\begin{array}{c}\text { Control } \\
\text { (4) }\end{array}$ & $\begin{array}{l}\text { Early } \\
(5)\end{array}$ & $\begin{array}{l}\text { Late } \\
(6)\end{array}$ & $\begin{array}{c}4=5 \\
(7)\end{array}$ & $\begin{array}{c}4=6 \\
(8)\end{array}$ & $\begin{array}{c}4=(5 \bigcup 6) \\
(9)\end{array}$ \\
\hline \multicolumn{10}{|c|}{ Panel A. Demographics, Labor, and Wealth } \\
\hline Age & $\begin{array}{l}39.19 \\
{[8.86]}\end{array}$ & $\begin{array}{l}39.37 \\
{[9.00]}\end{array}$ & 0.54 & $\begin{array}{l}38.91 \\
{[9.08]}\end{array}$ & $\begin{array}{l}39.60 \\
{[8.80]}\end{array}$ & $\begin{array}{l}39.38 \\
{[8.97]}\end{array}$ & 0.57 & 0.86 & 0.76 \\
\hline Years of education & $\begin{array}{c}4.69 \\
{[3.47]}\end{array}$ & $\begin{array}{c}4.36 \\
{[3.41]}\end{array}$ & 0.89 & $\begin{array}{c}4.41 \\
{[3.31]}\end{array}$ & $\begin{array}{c}4.72 \\
{[3.52]}\end{array}$ & $\begin{array}{c}4.30 \\
{[3.51]}\end{array}$ & 0.31 & 0.73 & 0.38 \\
\hline Can read newspaper in Odiya & $\begin{array}{c}0.63 \\
{[0.48]}\end{array}$ & $\begin{array}{c}0.64 \\
{[0.48]}\end{array}$ & 0.66 & $\begin{array}{c}0.61 \\
{[0.49]}\end{array}$ & $\begin{array}{c}0.65 \\
{[0.48]}\end{array}$ & $\begin{array}{c}0.66 \\
{[0.48]}\end{array}$ & 0.42 & 0.35 & 0.32 \\
\hline Primarily daily laborer & $\begin{array}{c}0.75 \\
{[0.43]}\end{array}$ & $\begin{array}{c}0.70 \\
{[0.46]}\end{array}$ & 0.27 & $\begin{array}{c}0.73 \\
{[0.45]}\end{array}$ & $\begin{array}{c}0.71 \\
{[0.45]}\end{array}$ & $\begin{array}{c}0.74 \\
{[0.44]}\end{array}$ & 0.84 & 0.77 & 0.99 \\
\hline Days of paid work in past 7 days & $\begin{array}{l}1.88 \\
{[2.12]}\end{array}$ & $\begin{array}{c}1.76 \\
{[1.77]}\end{array}$ & 0.43 & $\begin{array}{c}1.67 \\
{[1.96]}\end{array}$ & $\begin{array}{c}1.88 \\
{[1.99]}\end{array}$ & $\begin{array}{l}1.95 \\
{[1.81]}\end{array}$ & 0.34 & 0.27 & 0.24 \\
\hline Days of paid work in past 30 days & $\begin{array}{c}8.60 \\
{[6.31]}\end{array}$ & $\begin{array}{c}8.71 \\
{[6.47]}\end{array}$ & 0.88 & $\begin{array}{c}8.59 \\
{[6.90]}\end{array}$ & $\begin{array}{c}8.67 \\
{[5.94]}\end{array}$ & $\begin{array}{c}8.75 \\
{[6.26]}\end{array}$ & 0.96 & 0.89 & 0.92 \\
\hline Income quartile & $\begin{array}{c}2.39 \\
{[1.09]}\end{array}$ & $\begin{array}{c}2.42 \\
{[1.09]}\end{array}$ & 0.79 & $\begin{array}{c}2.41 \\
{[1.13]}\end{array}$ & $\begin{array}{c}2.46 \\
{[1.04]}\end{array}$ & $\begin{array}{c}2.31 \\
{[1.10]}\end{array}$ & 0.70 & 0.49 & 0.95 \\
\hline Lower financial strain (continuous) & $\begin{array}{c}0.41 \\
{[0.25]}\end{array}$ & $\begin{array}{c}0.38 \\
{[0.27]}\end{array}$ & 0.87 & $\begin{array}{c}0.39 \\
{[0.26]}\end{array}$ & $\begin{array}{c}0.40 \\
{[0.26]}\end{array}$ & $\begin{array}{c}0.39 \\
{[0.27]}\end{array}$ & 0.54 & 0.75 & 0.56 \\
\hline Lower financial strain (binary) & $\begin{array}{c}0.56 \\
{[0.50]}\end{array}$ & $\begin{array}{c}0.49 \\
{[0.50]}\end{array}$ & 0.49 & $\begin{array}{c}0.53 \\
{[0.50]}\end{array}$ & $\begin{array}{c}0.54 \\
{[0.50]}\end{array}$ & $\begin{array}{c}0.46 \\
{[0.50]}\end{array}$ & 0.83 & 0.55 & 0.90 \\
\hline Owns farmland & $\begin{array}{c}0.57 \\
{[0.50]}\end{array}$ & $\begin{array}{c}0.56 \\
{[0.50]}\end{array}$ & 0.76 & $\begin{array}{c}0.56 \\
{[0.50]}\end{array}$ & $\begin{array}{c}0.56 \\
{[0.50]}\end{array}$ & $\begin{array}{c}0.59 \\
{[0.49]}\end{array}$ & 0.90 & 0.39 & 0.62 \\
\hline Non-mud house & $\begin{array}{c}0.24 \\
{[0.43]}\end{array}$ & $\begin{array}{c}0.22 \\
{[0.41]}\end{array}$ & 0.92 & $\begin{array}{c}0.20 \\
{[0.40]}\end{array}$ & $\begin{array}{c}0.25 \\
{[0.43]}\end{array}$ & $\begin{array}{c}0.24 \\
{[0.43]}\end{array}$ & 0.25 & 0.24 & 0.17 \\
\hline No outstanding credits & $\begin{array}{c}0.46 \\
{[0.50]}\end{array}$ & $\begin{array}{c}0.46 \\
{[0.50]}\end{array}$ & 0.98 & $\begin{array}{c}0.47 \\
{[0.50]}\end{array}$ & $\begin{array}{c}0.46 \\
{[0.50]}\end{array}$ & $\begin{array}{c}0.45 \\
{[0.50]}\end{array}$ & 0.76 & 0.68 & 0.68 \\
\hline Can get Rs. $1 \mathrm{~K}$ in emergency & $\begin{array}{c}0.36 \\
{[0.48]}\end{array}$ & $\begin{array}{c}0.29 \\
{[0.45]}\end{array}$ & 0.45 & $\begin{array}{c}0.32 \\
{[0.47]}\end{array}$ & $\begin{array}{c}0.35 \\
{[0.48]}\end{array}$ & $\begin{array}{c}0.26 \\
{[0.44]}\end{array}$ & 0.46 & 0.61 & 0.76 \\
\hline $\mathrm{N}$ : workers & 183 & 224 & & 154 & 160 & 93 & & & \\
\hline
\end{tabular}

Notes: This table shows tests of differences in worker characteristics across treatment groups before treatments were implemented.

- Cols. 1-3 show balance for the early payment treatment and Cols. 4-9 for the priming treatment. Cols. 1-2 and 4-6 show the average value and standard deviation of each variable for one of the experimental conditions. Cols. 3 and 7-9 show the p-values of the coefficient from regressing each variable on indicator variables for the experimental conditions. All regressions control for round fixed effects. Robust standard errors are reported.

- All variables shown are either baseline characteristics or averages of participants' performance before the payment schedule is announced. To generate the financial strain index, we take a simple average of the last four binary variables in Panel A. Recall that high index values indicate lower financial strain. 
Table A2: Sample Characteristics and Baseline Balance across Experimental Arms (Cont'd)

\begin{tabular}{|c|c|c|c|c|c|c|c|c|c|}
\hline & \multicolumn{3}{|c|}{ Early-Pay Treatment } & \multicolumn{6}{|c|}{ Priming Treatment } \\
\hline & $\begin{array}{c}\text { Control } \\
\text { (1) }\end{array}$ & $\begin{array}{c}\text { Treatment } \\
\text { (2) }\end{array}$ & $\begin{array}{c}1=2 \\
(3)\end{array}$ & $\begin{array}{c}\text { Control } \\
(4)\end{array}$ & $\begin{array}{l}\text { Early } \\
(5)\end{array}$ & $\begin{array}{l}\text { Late } \\
(6)\end{array}$ & $\begin{array}{c}4=5 \\
(7)\end{array}$ & $\begin{array}{c}4=6 \\
(8)\end{array}$ & $\begin{array}{c}4=(5 \cup 6) \\
(9)\end{array}$ \\
\hline \multicolumn{10}{|l|}{ Panel B. Financial Worries and Loans } \\
\hline Very worried about finances & $\begin{array}{c}0.69 \\
{[0.46]}\end{array}$ & $\begin{array}{c}0.72 \\
{[0.45]}\end{array}$ & 0.57 & $\begin{array}{c}0.66 \\
{[0.48]}\end{array}$ & $\begin{array}{c}0.68 \\
{[0.47]}\end{array}$ & $\begin{array}{c}0.85 \\
{[0.36]}\end{array}$ & 0.76 & 0.00 & 0.13 \\
\hline Very worried about any loan & $\begin{array}{c}0.41 \\
{[0.49]}\end{array}$ & $\begin{array}{c}0.42 \\
{[0.49]}\end{array}$ & 0.71 & $\begin{array}{c}0.40 \\
{[0.49]}\end{array}$ & $\begin{array}{c}0.38 \\
{[0.49]}\end{array}$ & $\begin{array}{c}0.48 \\
{[0.50]}\end{array}$ & 0.61 & 0.35 & 0.93 \\
\hline Loan amounts very worried about (Rs.) & $\begin{array}{c}6,574 \\
{[12,645]}\end{array}$ & $\begin{array}{c}7,829 \\
{[16,396]}\end{array}$ & 0.95 & $\begin{array}{c}6,542 \\
{[12,654]}\end{array}$ & $\begin{array}{c}7,244 \\
{[15,658]}\end{array}$ & $\begin{array}{c}8,504 \\
{[16,674]}\end{array}$ & 0.81 & 0.65 & 0.69 \\
\hline Has loans & $\begin{array}{c}0.68 \\
{[0.47]}\end{array}$ & $\begin{array}{c}0.73 \\
{[0.45]}\end{array}$ & 0.57 & $\begin{array}{c}0.69 \\
{[0.46]}\end{array}$ & $\begin{array}{l}0.68 \\
{[0.47]}\end{array}$ & $\begin{array}{c}0.80 \\
{[0.41]}\end{array}$ & 0.70 & 0.10 & 0.65 \\
\hline Has moneylender loans & $\begin{array}{c}0.17 \\
{[0.38]}\end{array}$ & $\begin{array}{c}0.17 \\
{[0.38]}\end{array}$ & 0.60 & $\begin{array}{c}0.16 \\
{[0.36]}\end{array}$ & $\begin{array}{c}0.15 \\
{[0.36]}\end{array}$ & $\begin{array}{c}0.24 \\
{[0.43]}\end{array}$ & 0.80 & 0.20 & 0.63 \\
\hline Loan amount (Rs.) & $\begin{array}{c}10,846 \\
{[14,787]}\end{array}$ & $\begin{array}{c}12,409 \\
{[17,263]}\end{array}$ & 0.80 & $\begin{array}{c}10,829 \\
{[13,980]}\end{array}$ & $\begin{array}{c}11,807 \\
{[17,507]}\end{array}$ & $\begin{array}{c}12,992 \\
{[17,308]}\end{array}$ & 0.73 & 0.61 & 0.62 \\
\hline \multicolumn{10}{|c|}{ Panel C. Baseline Attendance and Productivity } \\
\hline Attendance & $\begin{array}{c}0.97 \\
{[0.11]}\end{array}$ & $\begin{array}{c}0.98 \\
{[0.09]}\end{array}$ & 0.58 & $\begin{array}{c}0.98 \\
{[0.09]}\end{array}$ & $\begin{array}{c}0.97 \\
{[0.12]}\end{array}$ & $\begin{array}{c}0.99 \\
{[0.06]}\end{array}$ & 0.29 & 0.35 & 0.63 \\
\hline Productivity & $\begin{array}{c}2.78 \\
{[1.46]}\end{array}$ & $\begin{array}{l}3.08 \\
{[1.35]}\end{array}$ & 0.39 & $\begin{array}{c}2.98 \\
{[1.73]}\end{array}$ & $\begin{array}{l}2.80 \\
{[1.15]}\end{array}$ & $\begin{array}{c}3.14 \\
{[1.19]}\end{array}$ & 0.10 & 0.86 & 0.24 \\
\hline Attentiveness index (continuous) & $\begin{array}{l}-0.23 \\
{[0.68]}\end{array}$ & $\begin{array}{l}-0.16 \\
{[0.76]}\end{array}$ & 0.97 & $\begin{array}{l}-0.30 \\
{[0.86]}\end{array}$ & $\begin{array}{l}-0.16 \\
{[0.62]}\end{array}$ & $\begin{array}{l}-0.08 \\
{[0.65]}\end{array}$ & 0.10 & 0.06 & 0.05 \\
\hline High attentiveness (binary) & $\begin{array}{c}0.36 \\
{[0.37]}\end{array}$ & $\begin{array}{c}0.40 \\
{[0.38]}\end{array}$ & 0.92 & $\begin{array}{c}0.36 \\
{[0.38]}\end{array}$ & $\begin{array}{c}0.39 \\
{[0.37]}\end{array}$ & $\begin{array}{c}0.42 \\
{[0.37]}\end{array}$ & 0.63 & 0.50 & 0.51 \\
\hline $\mathrm{N}$ stitches per plate & $\begin{array}{c}51.30 \\
{[10.30]}\end{array}$ & $\begin{array}{l}49.06 \\
{[9.51]}\end{array}$ & 0.05 & $\begin{array}{c}51.99 \\
{[11.04]}\end{array}$ & $\begin{array}{l}49.18 \\
{[9.14]}\end{array}$ & $\begin{array}{l}48.56 \\
{[8.81]}\end{array}$ & 0.03 & 0.02 & 0.01 \\
\hline $\mathrm{N}$ leaves per plate & $\begin{array}{l}14.74 \\
{[2.28]}\end{array}$ & $\begin{array}{l}14.50 \\
{[2.08]}\end{array}$ & 0.69 & $\begin{array}{l}14.66 \\
{[2.29]}\end{array}$ & $\begin{array}{l}14.66 \\
{[2.17]}\end{array}$ & $\begin{array}{l}14.42 \\
{[2.00]}\end{array}$ & 0.92 & 0.71 & 0.92 \\
\hline $\mathrm{N}$ double holes per plate & $\begin{array}{l}1.35 \\
{[1.14]}\end{array}$ & $\begin{array}{l}1.43 \\
{[1.84]}\end{array}$ & 0.14 & $\begin{array}{c}1.60 \\
{[1.96]}\end{array}$ & $\begin{array}{c}1.29 \\
{[1.14]}\end{array}$ & $\begin{array}{l}1.23 \\
{[1.46]}\end{array}$ & 0.09 & 0.25 & 0.10 \\
\hline $\begin{array}{l}\text { Joint Orthogonality Test } \\
\text { N: workers }\end{array}$ & 183 & 224 & 0.24 & 154 & 160 & 93 & & & 0.33 \\
\hline
\end{tabular}

Notes: This table is a continuation of Table A2, showing tests of differences in worker characteristics before treatments were implemented.

- Cols. 1-3 show balance for the early payment treatment and Cols. 4-9 for the priming treatment. Cols. 1-2 and 4-6 show the average value and standard deviation of each variable for one of the experimental conditions. Cols. 3 and 7-9 show the p-values of the coefficient from regressing each variable on indicator variables for the experimental conditions. All regressions control for round fixed effects. Robust standard errors are reported.

- All variables shown are either baseline characteristics or averages of participants' performance before the payment schedule is announced. Joint Orthogonality Test refers to the F-test of a regression of the early-pay or priming treatment dummy on all variables present in the balance table. This joint test provides an overall evaluation of the balance between groups being compared across all variables in the table. 
Table A3: Robustness: Impact of the Cash Infusion on Expenditure Patterns — Heterogeneity by Financial Strain (Binary)

\begin{tabular}{|c|c|c|c|c|}
\hline & \multicolumn{2}{|c|}{ Loans and Credits } & \multicolumn{2}{|c|}{ Expenditures } \\
\hline & $\begin{array}{c}\text { Any } \\
\text { Payment } \\
(1)\end{array}$ & $\begin{array}{l}\text { Amount } \\
\quad(2)\end{array}$ & $\begin{array}{l}\text { Food } \\
(3)\end{array}$ & $\begin{array}{c}\text { All } \\
\text { Expenses } \\
(4)\end{array}$ \\
\hline Cash & $\begin{array}{c}0.50^{* * *} \\
(0.06)\end{array}$ & $\begin{array}{c}258.71^{* * *} \\
(55.45)\end{array}$ & $\begin{array}{l}60.89^{*} \\
(31.20)\end{array}$ & $\begin{array}{c}389.63^{* * *} \\
(94.96)\end{array}$ \\
\hline Cash $\times$ Lower financial strain & $\begin{array}{c}-0.19^{* *} \\
(0.09)\end{array}$ & $\begin{array}{c}25.69 \\
(103.57)\end{array}$ & $\begin{array}{c}11.15 \\
(45.62)\end{array}$ & $\begin{array}{c}-34.41 \\
(134.63)\end{array}$ \\
\hline $\begin{array}{l}\text { P-val: cash effect }+ \text { interaction } \\
\mathrm{N} \text { : workers }\end{array}$ & $\begin{array}{c}0.000 \\
401\end{array}$ & $\begin{array}{c}0.001 \\
401\end{array}$ & $\begin{array}{c}0.041 \\
401\end{array}$ & $\begin{array}{c}0.000 \\
401\end{array}$ \\
\hline
\end{tabular}

Notes: This table presents the impact of the early-payment treatment on expenditure patterns.

- Regressions are similar to those in Table 1, Panel B. Instead of showing heterogeneous treatment effects using the continuous financial strain index, this table shows interactions with a a binary indicator that equals 1 if the worker has a below median level of financial strain (i.e. above median index value).

- Regressions are at the worker level, comparing average differences in expenditures in the 3 days following the cash infusion. "Cash" refers to whether an individual is in the early-payment treatment group.

- All regressions control for round fixed effects and an indicator for shorter experimental periods. Robust standard errors are reported. 
Table A4: The Impact of the Cash Infusion on Worker Productivity: Robustness Checks

\begin{tabular}{|c|c|c|c|c|c|c|}
\hline & \multicolumn{6}{|c|}{ Hourly Production } \\
\hline & (1) & $(2)$ & $(3)$ & $(4)$ & $(5)$ & $(6)$ \\
\hline Cash $\times$ Post-pay & $\begin{array}{c}0.250^{* * *} \\
(0.082)\end{array}$ & $\begin{array}{l}0.205^{* *} \\
(0.080)\end{array}$ & $\begin{array}{c}0.212^{* * *} \\
(0.079)\end{array}$ & $\begin{array}{c}0.215^{* * *} \\
(0.079)\end{array}$ & $\begin{array}{c}0.215^{* * *} \\
(0.079)\end{array}$ & $\begin{array}{c}0.239^{* * *} \\
(0.085)\end{array}$ \\
\hline Cash $\times$ Post-pay $\times$ Lower financial strain & $\begin{array}{c}-0.259^{* *} \\
(0.131)\end{array}$ & $\begin{array}{l}-0.191 \\
(0.117)\end{array}$ & $\begin{array}{c}-0.207^{*} \\
(0.117)\end{array}$ & $\begin{array}{c}-0.211^{*} \\
(0.117)\end{array}$ & $\begin{array}{c}-0.211^{*} \\
(0.117)\end{array}$ & $\begin{array}{c}-0.272^{* *} \\
(0.125)\end{array}$ \\
\hline Announcement controls & $\mathrm{Y}$ & $\mathrm{Y}$ & $\mathrm{Y}$ & $\mathrm{Y}$ & $\mathrm{Y}$ & $\mathrm{Y}$ \\
\hline Priming controls & $\mathrm{N}$ & $\mathrm{N}$ & $\mathrm{N}$ & $\mathrm{N}$ & Y & Y \\
\hline Include absent workers & $\mathrm{N}$ & $\mathrm{N}$ & $\mathrm{N}$ & $\mathrm{N}$ & $\mathrm{N}$ & Y \\
\hline Fixed effects included & Round & Worker & Worker, day & $\begin{array}{c}\text { Worker, } \\
\text { day, } \\
\text { round-hour }\end{array}$ & $\begin{array}{c}\text { Worker, } \\
\text { day, } \\
\text { round-hour }\end{array}$ & $\begin{array}{c}\text { Worker, } \\
\text { day, } \\
\text { round-hour }\end{array}$ \\
\hline $\mathrm{N}$ : worker-hours & 22,789 & 22,789 & 22,789 & 22,789 & 22,789 & 23,217 \\
\hline
\end{tabular}

Notes: This table shows robustness of the early-payment treatment effects to alternate specifications.

- Col. 5 of this table corresponds to the exact specification in Col. 2 of Table 2 Panel B. The remaining regressions show robustness to alternate specifications. Standard errors are clustered by worker in all regressions.

- "Cash" refers to whether an individual is in the early-payment treatment group. "Post-pay" indicates the period after cash infusion. "Lower financial strain" is an indicator that equals 1 if the worker has a below median level of financial strain by this index measure (i.e. above median index value).

- In Col. 1, regressions include announcement controls, round fixed effects, and dummies for shorter production slot lengths. Regressions in Cols. 2-4 are similar to the one in Col. 1, but successively includes more controls for worker, day, and round times hour-of-the-day fixed effects. The regression in Col. 5 additionally includes priming controls.

- The regression in Col. 6 adds in worker-days when a worker was absent, with output coded as zero for that day. The specification in this column is otherwise the same as that in Col. 5 . 
Table A5: Persistence of Cash Infusion Impacts

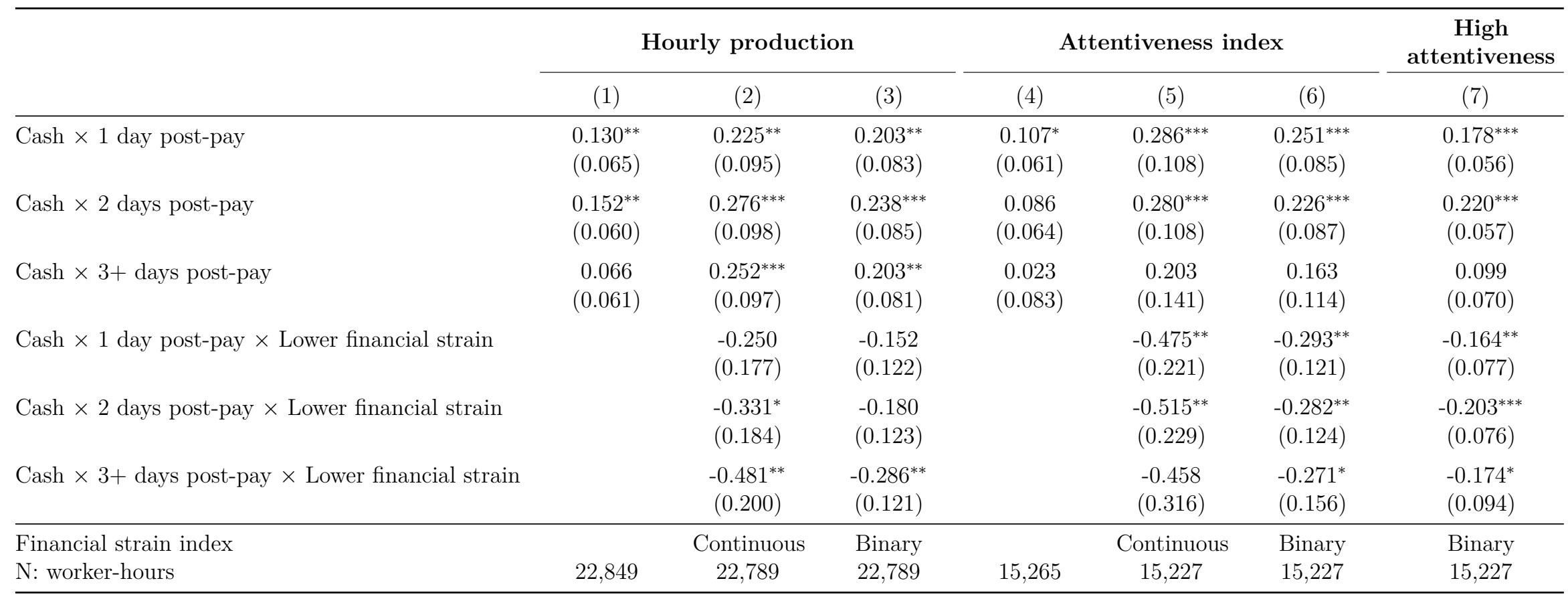

Notes: This table shows treatment effects of the early-pay treatment separately for each day of the Post-pay period.

- The dependent variables are normalized hourly production (Cols. 1-3), the attentiveness index (Cols. 4-6), and a dummy for whether the attentiveness index is above the median (Col. 7).

- "1 day (2 or $3+$ days) post-pay" is a dummy capturing whether the participant received payment 1 day ago (2 or $3+$ days ago). We interact these variables with the continuous financial strain index (Cols. 2 and 5) and the lower financial strain binary indicator (Cols. 3, 6, and 7).

- All regressions include our standard set of controls: worker, day, and round times hour-of-the-day fixed effects, as well as announcement controls, priming controls, and dummies for shorter production slot lengths. Standard errors are clustered by worker. 
Table A6: Impact of the Cash Infusion on Worker Productivity: Additional Outcomes

\begin{tabular}{|c|c|c|c|}
\hline & $\begin{array}{l}\text { Attendance } \\
\text { (1) }\end{array}$ & $\begin{array}{l}\text { Share of } \\
\text { rejections } \\
(2)\end{array}$ & $\begin{array}{l}\text { Normalized } \\
\text { hourly } \\
\text { production } \\
(3)\end{array}$ \\
\hline Cash $\times$ Post-pay & $\begin{array}{c}-0.012 \\
(0.016)\end{array}$ & $\begin{array}{c}0.009 \\
(0.006)\end{array}$ & $\begin{array}{l}0.118^{* *} \\
(0.057)\end{array}$ \\
\hline $\begin{array}{l}\text { Control group mean } \\
\text { Include rejections } \\
\mathrm{N} \text { : worker-days } \\
\mathrm{N} \text { : worker-hours }\end{array}$ & $\begin{array}{l}0.983 \\
4,039\end{array}$ & 22,722 & $\begin{array}{c}0.031 \\
\mathrm{Y} \\
22,849\end{array}$ \\
\hline
\end{tabular}

Notes: This table shows the impact of the early-payment treatment on worker attendance and productivity using alternate sample restrictions and productivity measures.

- In Col. 1, the dependent variable is attendance, a day-level variable indicating whether worker was present at the work site. Regressions control for worker and day fixed effects, as well as announcement controls.

- In Col. 2, the dependent variable is the share of rejections, which corresponds to the number of plates that did not meet quality standards (see Figure A.1) out of all the plates produced in the hour.

- Col. 3 corresponds to Col. 4 in Panel A, Table 2, but the dependent variable is normalized hourly production including rejections. The total number of plates produced per hour (including rejections) is normalized using the control group's total production (mean and standard deviation) in the post-pay period.

- In Col. 2-3, regressions include our standard set of controls: worker, day, and round times hour-of-the-day fixed effects, as well as announcement controls, priming controls, and dummies for shorter production slot lengths. Standard errors in all columns are clustered by worker. 
Table A7: Correlation Between Worker Productivity, Attentiveness, and Cognition

PANEL A: Main rounds-Productivity and Attentiveness

\begin{tabular}{lccccc} 
& $\begin{array}{c}\text { Attentiveness } \\
\text { index } \\
(1)\end{array}$ & $\begin{array}{c}\text { High atten- } \\
\text { tiveness } \\
(2)\end{array}$ & $\begin{array}{c}\text { Number of } \\
\text { leaves } \\
(3)\end{array}$ & $\begin{array}{c}\text { Number of } \\
\text { stitches } \\
(4)\end{array}$ & $\begin{array}{c}\text { Number of } \\
\text { double holes } \\
(5)\end{array}$ \\
\hline Hourly production & $\begin{array}{c}0.422^{* * *} \\
(0.072)\end{array}$ & $\begin{array}{c}0.190^{* * *} \\
(0.039)\end{array}$ & $\begin{array}{c}-0.337^{* * *} \\
(0.089)\end{array}$ & $\begin{array}{c}-0.728^{* * *} \\
(0.186)\end{array}$ & $\begin{array}{c}-0.519^{* * *} \\
(0.115)\end{array}$ \\
\hline N: workers & 340 & 340 & 340 & 259 & 340 \\
\hline
\end{tabular}

PANEL B: Supplementary rounds-Productivity, Attentiveness, and Cognition

\begin{tabular}{lccccc} 
& $\begin{array}{c}\text { Attentiveness } \\
\text { index } \\
(1)\end{array}$ & $\begin{array}{c}\text { High atten- } \\
\text { tiveness } \\
(2)\end{array}$ & $\begin{array}{c}\text { CORSI } \\
\text { performance } \\
(3)\end{array}$ & $\begin{array}{c}\text { Attentiveness } \\
\text { index } \\
(4)\end{array}$ & $\begin{array}{c}\text { High atten- } \\
\text { tiveness } \\
(5)\end{array}$ \\
\hline Hourly production & $0.384^{* * *}$ & $0.236^{* * *}$ & $1.289^{* * *}$ & & \\
& $(0.070)$ & $(0.041)$ & $(0.284)$ & & $0.044^{* * *}$ \\
CORSI performance & & & & $(0.015)$ & $0.027^{* * *}$ \\
& & & & 145 & 145 \\
\hline N: workers & 150 & 150 & 145 & 145
\end{tabular}

Notes: This table shows the cross-sectional relationships between worker productivity, attentiveness, and cognition.

- Panel A shows the relationship between baseline productivity and attentiveness using baseline (i.e. pre-announcement) observations from the main experiment sample. Data are from the longer rounds with full baseline periods, i.e. rounds 1-12. Worker-level averages are calculated using observations prior to announcement. The attentiveness index is an average of three normalized proxies for attentiveness: the average number of leaves, stitches, and double holes (which signify that a stitch was removed in order to correct mistake) per plate during the production hour slot. The scale is reversed so that a higher value on the index corresponds to improved attentiveness (i.e. fewer double holes, leaves, or stitches). High attentiveness indicates that the index value is greater than the sample median.

- Panel B shows the relationship between productivity, attentiveness, and cognitive function using the data from the supplementary piece rate rounds. Worker-level averages are calculated using observations after the first (training) day. Corsi performance is worker's score on an incentivized memory test (Corsi Span Test, see a detailed description in Dean et al. (2018)). Average score was 9 out of 15 with standard deviation of 2.4. All regressions control for round fixed effects. Standard errors are clustered by worker. 
Table A8: Impact of Piece Rate Variation: Heterogeneity by Financial Strain

\begin{tabular}{|c|c|c|c|c|c|}
\hline & \multicolumn{2}{|c|}{ Hourly production } & \multicolumn{2}{|c|}{ Attentiveness index } & \multirow{2}{*}{$\begin{array}{c}\text { Attendance } \\
(5)\end{array}$} \\
\hline & $(1)$ & $(2)$ & $(3)$ & $(4)$ & \\
\hline Piece rate & $\begin{array}{c}0.017 \\
(0.013)\end{array}$ & & $\begin{array}{l}-0.011 \\
(0.014)\end{array}$ & & $\begin{array}{c}0.001 \\
(0.012)\end{array}$ \\
\hline Piece rate $=$ Rs. 3 & & $\begin{array}{c}0.040^{*} \\
(0.022)\end{array}$ & & $\begin{array}{c}0.039 \\
(0.039)\end{array}$ & \\
\hline Piece rate $=$ Rs. 4 & & $\begin{array}{c}0.035 \\
(0.026)\end{array}$ & & $\begin{array}{l}-0.023 \\
(0.028)\end{array}$ & \\
\hline Piece rate $\times$ Lower financial strain & $\begin{array}{l}-0.000 \\
(0.017)\end{array}$ & & $\begin{array}{c}0.005 \\
(0.019)\end{array}$ & & $\begin{array}{l}-0.001 \\
(0.013)\end{array}$ \\
\hline Piece rate $=$ Rs. $3 \times$ Lower financial strain & & $\begin{array}{c}-0.034 \\
(0.029)\end{array}$ & & $\begin{array}{l}-0.065 \\
(0.049)\end{array}$ & \\
\hline Piece rate $=$ Rs. $4 \times$ Lower financial strain & & $\begin{array}{l}-0.000 \\
(0.033)\end{array}$ & & $\begin{array}{c}0.011 \\
(0.038)\end{array}$ & \\
\hline Include absent workers & $\mathrm{N}$ & $\mathrm{N}$ & $\mathrm{N}$ & $\mathrm{N}$ & $\mathrm{Y}$ \\
\hline P-val: equality of coefficients & & & & & \\
\hline Piece rate in $(1)$ and $(3)$ & 0.056 & & & & \\
\hline Piece rate $=$ Rs. 3 in (2) and (4) & & 0.995 & & & \\
\hline Piece rate $=$ Rs. 4 in $(2)$ and $(4)$ & & 0.054 & & & \\
\hline Piece rate $\times$ Lower financial strain in $(1)$ and $(3)$ & 0.772 & & & & \\
\hline Piece rate $=$ Rs. $3 \times$ Lower financial strain in $(2)$ and $(4)$ & & 0.473 & & & \\
\hline Piece rate $=$ Rs. $4 \times$ Lower financial strain in (2) and (4) & & 0.765 & & & \\
\hline $\mathrm{N}$ : worker-hours & 4,344 & 4,344 & 4,343 & 4,343 & \\
\hline $\mathrm{N}$ : worker-days & & & & & 898 \\
\hline
\end{tabular}

Notes: This table shows the impact of changing piece-rates on work outcomes. The table closely follows Table 4 and additionally includes interactions with the financial strain index.

- The dependent variables are normalized hourly production in Cols. 1-2, the attentiveness index in Cols. 3-4, and attendance in Col. 5. The production and attentiveness measures are worker-hour level variables, normalized using the same control group mean and standard deviations as the measures in the main rounds. Attendance is a worker-day level variable indicating whether worker was present at the work site.

- "Lower financial strain" is a binary indicator that equals 1 if the worker has a below median level of financial strain (i.e. above median index value). Regressions in Cols. 1-4 control for individual, day, and round times hour-of-the-day fixed effects, and also include controls for shorter production slot lengths. The regression in Col. 5 controls for individual and day effects. Standard errors are clustered by worker. 


\begin{tabular}{|c|c|c|c|c|}
\hline & $(1)$ & $(2)$ & $(3)$ & $(4)$ \\
\hline Post-priming & $\begin{array}{l}0.044^{* *} \\
(0.022)\end{array}$ & $\begin{array}{c}0.078^{*} \\
(0.045)\end{array}$ & $\begin{array}{c}0.084 \\
(0.059)\end{array}$ & $\begin{array}{c}-0.008 \\
(0.059)\end{array}$ \\
\hline Post-priming $\times$ Pre-payment & & $\begin{array}{l}-0.055 \\
(0.057)\end{array}$ & $\begin{array}{c}-0.071 \\
(0.069)\end{array}$ & $\begin{array}{c}0.057 \\
(0.078)\end{array}$ \\
\hline Post-priming $\times$ Lower financial strain & & & $\begin{array}{l}-0.056 \\
(0.082)\end{array}$ & \\
\hline Post-priming $\times$ Pre-payment $\times$ Lower financial strain & & & $\begin{array}{c}0.084 \\
(0.105)\end{array}$ & \\
\hline Post-priming $\times$ High worrisome loans & & & & $\begin{array}{c}0.178^{* *} \\
(0.088)\end{array}$ \\
\hline Post-priming $\times$ Pre-payment $\times$ High worrisome loans & & & & $\begin{array}{c}-0.250^{* *} \\
(0.107)\end{array}$ \\
\hline P-val: sum of top two coefficients & & 0.407 & 0.706 & 0.230 \\
\hline P-val: sum of all four coefficients & & & 0.337 & 0.418 \\
\hline $\mathrm{N}$ : worker-hours & 22,849 & 22,849 & 22,789 & 22,730 \\
\hline
\end{tabular}

Notes: This table shows the impact of the priming intervention on worker productivity.

- "Post-priming" is an indicator that equals 1 if the individual received the priming intervention earlier that day. "Pre-payment" is an indicator that equals 1 on the days before the Post-payment period for the worker's wave.

- "Lower financial strain" is an indicator that equals 1 if the worker has a below median level of financial strain (i.e. above median index value). "High worrisome loans" indicates that the total amount of loans about which the worker reported being very worried at baseline is greater than sample median.

- All regressions include variables to account for the effects of the early-payment treatment, i.e. an indicator for the post-payment period and its interaction with being in the early-payment treatment group. Regressions also include controls for worker, day, and round times hour-of-the-day fixed effects, as well as announcement controls, priming controls, and dummies for shorter production slot lengths. Standard errors are clustered by worker. 


\section{A.2 Protocols Appendix}

This appendix provides additional detail on the study protocols.

Standard round timing. The standard schedule refers to the 12-day, 5-hour work schedule with a base rate of Rs. 200 and a piece rate of Rs. 3 per plate, implemented for rounds 4 to 12 of the study. In those rounds, the payment schedule was announced at the beginning of day 5 . Within each round, the treatment and control groups were each divided into two Wave A and Wave B:

- For Wave A treatment workers, the early payment happened at the end of the day 8. For those assigned to receive either early or late priming in Wave A, priming sessions were conducted on day 6 or 10 .

- For Wave B treatment workers, the early payment occurred on day 9. For Wave $\mathrm{B}$ treatment and control workers who were assigned to receive priming, priming sessions were randomized to occur a day later than Wave A, on day 7 or 11 .

- For the early pay treatment, workers received wages earned up to one day before the payday, i.e. payment lag was one day.

Any deviations from this standard schedule is described below and are summarized in Panel A of Appendix Table A10.

Deviations. There were several deviations from from the standard schedule:

- Rounds 1-3, which were conducted in March-June of 2017, had a number of deviations from the standard schedule and wage rates, which were later finalized and then implemented during March-June of 2018. During these rounds, each workday contained 7 hours of work and a lunch break, rather than 5 continuous hours of work without lunch. Both types of work day schedules are common in the local region. Some workers expressed their preferences for shorter work days due to hot weather, so the daily schedules were updated in 2018. Workers with the 5-hour schedules still received a snack at the end of each day.

- The later rounds (rounds 12-14) were shortened in order to avoid running the experiment into the transplanting season. Round 12 follows the standard schedule 
but is shortened by one day. Its schedule is equivalent to skipping day 5 and having the announcement of the payment schedule on day 6 .

- Round 13-14 were shorted to 6 days. The payment schedule was not separately announced during round 13, but was announced on day 2 in round 14 . In order to make the size of the early payments comparable to the other rounds, the earlypay group's initial payment included a bonus of Rs. 200 in addition to all wages earned up to the payment day (i.e. including the first day's wage). The control group received this bonus on the last day, along with other payments. Workers also received an attendance bonus of Rs. 200 if they missed none of the last five workdays.

- While most rounds had consecutive work days, some rounds had one-day breaks in the first half of the rounds due to local events and religious festivals. Specifically, there were one-day breaks after day 5 in round 2, after day 2 of round 3, and after day 3 of round 12 .

Supplementary piece rate rounds. In the supplementary piece-rate rounds (conducted after the 14 main experimental rounds had been completed), there was no variation in the payment schedule: all workers were paid all their post-training earnings on the final day. During these rounds, we induced random variation in piece rates across days. As in the main experimental rounds, workers received a flat wage of Rs. 250 with no piece-rate component on the first day. In the remaining six days, workers were paid a piece rate of Rs. 2, 3, and 4. Each workers received each of the three piece rates for two consecutive days, with the order of piece rates randomized across workers. The base wage was adjusted so that average daily earnings would be approximately similar for all three piece rates. To do this, we calibrated the base wage based on workers' average productivity during the main rounds. The base wage rates for each round are described in Panel B of Appendix Table A10. 
Table A10: Schedule and Wage Summary

PANEL A: Main Rounds Schedule and Wage

\begin{tabular}{lccccc} 
& Round 1 & Round 2 & Round 3 & $\begin{array}{c}\text { Round } \\
\mathbf{4 - 1 2}\end{array}$ & $\begin{array}{c}\text { Round } \\
13-14\end{array}$ \\
\hline Total days & 12 & 11 & 12 & $\mathbf{1 2 *}$ & 6 \\
Work hours per day & 7 & 7 & 7 & $\mathbf{5}$ & 5 \\
Baseline survey & Day 1 & Day 2 & Day 2 & Day $\mathbf{1}$ & Day 1 \\
Schedule announcement & Day 5 & Day 5 & Day 5 & Day $\mathbf{5} *$ & Day $2 \dagger$ \\
First priming session & Day $7 / 8$ & Day $7 / 8$ & Day $8 / 9$ & Day $\mathbf{6} / \mathbf{7}$ & Day $3 / 4$ \\
Early-Pay Treatment & Day $8 / 9$ & Day $8 / 9$ & Day $9 / 10$ & Day $\mathbf{8} / \mathbf{9}$ & Day $3 / 4$ \\
Second priming session & Day $10 / 11$ & Day $10 / 11$ & Day $11 / 12$ & Day $\mathbf{1 0 / 1 1}$ & Day $5 / 6$ \\
Endline survey & Day $11-12$ & Day 11 & Day 12 & Day $\mathbf{1 2}$ & Day 6 \\
First day flat wage & 230 & 250 & 250 & $\mathbf{2 5 0}$ & 250 \\
Base wage & 200 & 180 & 175 & $\mathbf{2 0 0}$ & 200 \\
Piece-rate wage & 2 & 3 & 3 & $\mathbf{3}$ & 3 \\
Attendance bonus & 350 & 350 & 350 & $\mathbf{3 0 0}$ & $400 \ddagger$ \\
Payment lag & 2 days & 2 days & 2 days & $\mathbf{1}$ day & 0 day \\
\hline
\end{tabular}

PANEL B: Supplementary Rounds Wage

\begin{tabular}{lccccc} 
& Round 15 & Round 16 & Round 17 & Round 18 & Round 19 \\
\hline Base wage when piece-rate $=2$ & 230 & 240 & 230 & 240 & 220 \\
Base wage when piece-rate $=3$ & 215 & 220 & 205 & 220 & 200 \\
Base wage when piece-rate $=4$ & 200 & 200 & 180 & 200 & 180 \\
\hline
\end{tabular}

Notes: This table shows key features of the different experimental rounds. Panel A shows information for the main rounds, while Panel B shows information for the supplementary piece rate rounds.

* Round 4-11 all involved 12 days. Round 12 followed the standard schedule but is shorter by one day. Its schedule was equivalent to skipping day 5 and having the schedule announcement on day 6 .

$\dagger$ Payment schedule was announced on day 2 in round 14. However, in round 13, payment schedule was never separately announced.

$\ddagger$ In rounds 13-14, everyone received a bonus of Rs. 200 (which was combined with the Early-Pay Treatment for the Early-Pay Group), and the attendance bonus was Rs. 200. Hence the total amount of bonus was 400. 